\title{
Fast photoswitchable molecular prosthetics control neuronal activity in the cochlea
}

Aida Garrido-Charles ${ }^{1,2,3,4^{*}}$, Antoine Huet ${ }^{3,4,5,6^{*}}$, Carlo Matera ${ }^{1,2, \S^{*}}$, Anupriya Thirumalai ${ }^{3,4,5}$, Amadeu Llebaria7, Tobias Moser ${ }^{3,4,6^{\sim}}$, Pau Gorostiza ${ }^{1,2,8^{\sim}}$

${ }^{1}$ Institute for Bioengineering of Catalonia (IBEC), Barcelona Institute for Science and Technology, Carrer de Baldiri Reixac 15-21, 08028 Barcelona, Spain

${ }^{2}$ Network Biomedical Research Center in Bioengineering, Biomaterials, and Nanomedicine (CIBERBBN), 28029 Madrid, Spain

${ }^{3}$ Institute for Auditory Neuroscience and InnerEarLab, University Medical Center Göttingen, 37075 Göttingen, Germany.

${ }^{4}$ Auditory Neuroscience and Optogenetics Group, German Primate Center, 37077 Göttingen, Germany.

${ }^{5}$ Auditory Circuit Lab, Institute for Auditory Neuroscience and InnerEarLab, University Medical Center Göttingen, Germany

${ }^{6}$ Cluster of Excellence "Multiscale Bioimaging: from Molecular Machines to Networks of Excitable Cells" (MBExC), University of Göttingen, Germany

${ }^{7}$ Institute of Advanced Chemistry of Catalonia, Consejo Superior de Investigaciones Científicas (IQAC-CSIC), 08034 Barcelona, Spain.

${ }^{8}$ Catalan Institution for Research and Advanced Studies (ICREA), 08010 Barcelona, Spain

${ }^{*}$ These authors contributed equally to this work

־These authors contributed equally to this work; e-mail: tmoser@gwdg.de (T.M.), pau@icrea.cat (P.G.)

$\S$ present address: Department of Pharmaceutical Sciences, University of Milan, 20133 Milan, Italy

\section{ABSTRACT}

Artificial control of neuronal activity enables studies of neural circuits and restoration of neural function. Direct, rapid, and sustained photocontrol of intact neurons could overcome shortcomings of established electrical stimulation such as poor selectivity. We have developed fast photoswitchable ligands of glutamate receptors to establish such control in the auditory system. The new photoswitchable ligands produced photocurrents in untransfected neurons upon covalently tethering to endogenous glutamate receptors and activating them reversibly with visible light pulses of few milliseconds. As a proof of concept of these molecular prostheses, we apply them to the ultrafast synapses of auditory neurons of the cochlea that encode sound and provide auditory input to the brain. This drug-based method affords kilohertz rate stimulation of auditory neurons of adult gerbils without genetic manipulation that would be required for their optogenetic control. The new photoswitchable ligands are also broadly applicable to spatiotemporally control fast spiking interneurons in the brain. 


\section{INTRODUCTION}

Ultrafast signaling is a feature of several important neural circuits such as in inner ear, the brainstem, the cerebellum and the cerebrum (Kaczmarek \& Zhang, 2017; Hu et al, 2014; Grothe et al, 2010). Such signaling builds on specialized synapses for synchronous neurotransmission as well as on suitable neural membrane properties for action potential generation and propagation. The resulting neural firing features high rates and submillisecond precision. For an example, synaptic sound encoding builds on ultrafast glutamatergic transmission at specialized ribbon synapses achieving firing at rates of several hundreds of Hertz with submillisecond precision (Huet et al, 2016; Moser et al, 2019). Utmost precision of the neural time code of the incoming sound forms the basis of sound localization in dedicated neural circuits of the brainstem that feature powerful calyceal synapses and neurons with extremely short membrane time constants owing to their specialized set of ion channels (Kaczmarek \& Zhang, 2017; Grothe et al, 2010).

Dissecting the function of such time-critical neural circuitries requires ultrafast control of neuronal activity. Likewise, functional restoration, for example, following degeneration of the sensory receptor cells, needs approaches that re-instate the physiological behavior as closely as possible. Restoration of hearing to the deaf currently employs electrical stimulation of spiral ganglion neurons (SGNs) by cochlear implants (Cl, (Kleinlogel et al, 2020; Zeng, 2017; Lenarz, 2017). Due to wide spread of current from each electrode contact encoding of sound frequency information is heavily limited in Cls. Moreover, electrical SGN stimulation results in supernatural temporal precision of spiking and hence Cls employ high rates to generate pseudostochasticity of SGN firing. Recently, optogenetics has been proposed for improved bionic SGN stimulation, as light can be better confined in space and optogenetically-evoked firing shows near-physiological temporal fidelity. Yet, it requires genetic manipulation for expression of channelrhodopsins. Avoiding the need of gene therapy, photopharmacology could help reducing the complexity of optical SGN stimulation. Reversibility of chemical photoswitches (Ankenbruck et al, 2018) make them interesting candidates for controlling neural excitation via endogenous neuronal receptors, such as ionotropic glutamate receptors of the postsynaptic SGN boutons in the cochlea.

Photoswitchable tethered ligands (PTLs) which are covalently attached to their receptor seem particularly attractive for this purpose as they provide more precise photocontrol than freely diffusible photochromic ligands (PCLs). PTLs produce higher local concentrations (Gorostiza et al, 2007) and cannot diffuse away, which yields a sharper separation in biological activity between the two isomeric states (Hüll et al, 2018; Reiner \& Isacoff, 2014). Genetic manipulation can be avoided with affinity labeling conjugation of PTLs to target native nucleophilic residues in the protein (e.g. lysine (Izquierdo-Serra et al, 2016), histidine (Harvey \& Trauner, 2008)). These targeted covalent photoswitches (TCPs) can be applied to intact neurons and readily provide photocontrol for hours (Izquierdo-Serra et al, 2016). However, their bistable i.e. dual-color, slow-relaxing photochromism (Volgraf et al, 2006; Gorostiza \& Isacoff, 2007, 2008; Berlin et al, 2016; Kienzler \& Isacoff, 2017) has so far hindered their application to ultrafast synapses. Thus, methods for direct, rapid and sustained photocontrol of activity in intact neurons constitute an unmet need, both to study neuronal circuits for basic research purposes and to explore new phototherapies. Interestingly, when sensory neurons are damaged or absent, fast and sustained neurotransmitter release is impaired, but the postsynaptic neurons and receptors retain their full capacities (activation kinetics, localization, 
complex formation with regulatory proteins) for extended periods of time, offering untapped potential for functional restoration (Kleinlogel et al, 2020).

Here, we developed a fast-switching glutamate TCP (TCP fast, Figure 1.A) that fulfills the above-mentioned requirements. We show the ability of $\mathrm{TCP}_{\text {fast }}$ to produce photocurrents in naive hippocampal neurons likely via tethering to endogenous glutamate receptors and reversibly modulating their activity with visible light pulses as short as a few milliseconds. As an original proof of concept, we demonstrate the application of this molecular tool to the ultrafast first synapses of the auditory system formed by inner hair cells (IHCS) and spiral ganglion neurons (SGNs), which mediate cochlear sound encoding. This drug-based method affords kilohertz rate stimulation in cochlear SGNs of wildtype adult gerbils, matching the performance of optogenetic photostimulation that requires gene therapy. In general, these photoswitches provide a fundamental resource of broad interest to spatiotemporally control endogenous receptors in intact neuronal circuits with ultrafast signaling.

\section{RESULTS}

\section{Design and synthesis of a fast-switching TCP of ionotropic glutamate receptors.}

The molecular design of TCP fast $(3)$ was based on the recently reported TCPs (Izquierdo-Serra et al, 2016) and is shown in Figure 1.A. TCPs have a modular structure obtained by combining a 'head', which bears both the bioactive ligand (glutamate moiety) and the photoisomerizable unit (azobenzene) (Supplementary Scheme S1), and a 'tail' bearing the anchoring group (NHS ester). NHS ester-activated linkers are short-lived groups that promptly react with primary amines (e.g., lysine residues) in neutral or slightly alkaline conditions ( $\mathrm{pH}$ 7.2-9). To avert self-reactivity, TCPs are readily generated prior to attachment to the target protein via a copper(I)-catalyzed azide-alkyne cycloaddition reaction (CuAAC, also known as "click chemistry") (Supplementary Scheme S2).

Previous TCPs featured azobenzene moieties that were photoisomerized using two different illumination wavelengths (380 and $500 \mathrm{~nm}$ ) and characterized by slow thermal cis-to-trans relaxation (Izquierdo-Serra et al, 2016). Azobenzenes displaying faster relaxation kinetics and single, longer wavelength switching can be obtained with minimal variation of their chemical structure by generating a "push-pull" system. It consists of including electron donating groups on one side of the azo unit and electron withdrawing groups on the other to lower the energy barrier of the cis-to-trans isomerization (Chi et al, 2006; Bandara \& Burdette, 2012). This also results in a red-shifting of the azobenzene absorption spectrum, which is useful to reduce light scattering and the potential phototoxicity, which is greater for violet light, for in vivo application. Thus, we designed a TCP fast head in which one of the two amide groups at the para positions of the azobenzene was replaced by a tertiary amine as electron-donating group (Kienzler et al, 2013). To avoid perturbing the ligand region, we chose to introduce this modification on the opposite side of the azobenzene core (head compound 1). Compound 1 was prepared via a 5-step synthesis starting from commercially available materials (Supplementary Scheme S1 and SI for details). This photoswitch showed an absorption maximum at about $460 \mathrm{~nm}$ (blue light) in aqueous solution at neutral $\mathrm{pH}$, as previously reported (see $\mathrm{SI}$ ). Moreover, no variation of the absorption spectrum could be detected by steady-state UV-Vis spectroscopy, suggesting that it rapidly $(<1 \mathrm{~s})$ relaxes back to trans when the 
light is turned off. The head (1) was coupled via CuAAC with a commercial tail (compound 2) providing a fast-relaxing and red-shifted ligand (3) with similar length to TCP9 (Izquierdo-Serra et al, 2016) (Figure 1.B and Supplementary Scheme S2). In order to reach satisfactory head-tail coupling rate in minutes at room temperature, we replaced the conventional sodium ascorbate by ascorbic acid (see SI for details). We hypothesized that the buffering effect of the ascorbic acid (to the tertiary amine in compound 1 ) could create more proper conditions to promote the catalytic cycle of the reaction (Shao et al, 2010) as well as favor the formation of active copper(I) species from the copper(I) oxide catalyst (Shao et al, 2011). Since NHS-based ligands are constitutively short-lived, we confirmed the formation of the desired $\mathrm{TCP}_{\text {fast }}$ by liquid chromatography-mass spectrometry (LC-MS) of the click reaction crudes and verified their ability to conjugate primary amine-containing biomolecules by reacting them with pure lysine as a mock protein residue (see SI for details).

\section{Characterization of TCP fast in cultured neurons}

We made use of the several glutamate receptors (GluR) subunits expressed by hippocampal neurons (Janssens \& Lesage, 2001) to evaluate, on dissociated neuron cultures, the ability of TCP fast to photocontrol glutamate receptor activity. TCP fast was conjugated to GluRs by using the same incubation conditions (i.e. $2 \mathrm{~min}$ at $25-100 \mu \mathrm{M}, \mathrm{pH} 9$ to favor deprotonation and reactivity of nucleophilic residues in the receptors followed by wash-out of physiological solution, $\mathrm{pH} 7.4$ ) previously shown to be favorable for TCP conjugation (Izquierdo-Serra et al, 2016). Using whole cell patch clamp recordings, $473 \mathrm{~nm}$ illumination did not elicit photocurrent directly after incubation with $\mathrm{TCP}_{\text {fast. }}$. However, in the additional presence of glutamate $(300 \mu \mathrm{M}), 473 \mathrm{~nm}$ illumination elicited 2.5-220 pA photocurrents (Supplementary Figure S13). As intended by the chemical design, the cis isomer of $\mathrm{TCP}_{\text {fast}}$, induced by blue light illumination, evoked inward photocurrents thus supporting the fact that $\mathrm{TCP}_{\text {fast }}$ enabled photomodulation of glutamate receptors. Next, we tested the effect of light in absence of $\mathrm{TCP}_{\text {fast }}$ incubation (Supplementary Figure S14). The current measured at the onset of $300 \mu \mathrm{M}$ glutamate perfusion were of similar amplitude in both cases (793 $\pm 131 \mathrm{pA}$ with $\mathrm{TCP}_{\text {fast }}$ and $1161 \pm 445 \mathrm{pA}$ without $\left.\mathrm{TCP}_{\text {fast }}\right)$, discarding any non-specific effect of light stimulation.

Next, we showed that the number of photosensitized hippocampal neurons and the amplitude of the photocurrent evoked by blue light (Supplementary Figure S15) increased with $\mathrm{TCP}_{\text {fast }}$ concentration during the incubation $(25,50,75$ and $100 \mu \mathrm{M})$. At $25 \mu \mathrm{M}$ of TCP fast, $47.62 \%$ of neurons $(n=21)$ had a measurable photocurrent (on average: $25 \pm 12 \mathrm{pA}$ ) while $100 \mu \mathrm{M}$ raised this to $90 \%$ of the neurons $(n=11)$ with a photocurrent of $93 \pm 25 \mathrm{pA}$. In contrast, the TCP fast relaxation lifetime in the dark seemed to be independent of TCP fast concentration, amounted to $220 \pm 48 \mathrm{~ms}$ (Supplementary Figure S16) and was, in accordance with our chemical design, faster than shown for TCPs ( 80 min) (Izquierdo-Serra et al, 2016). For a subset of neurons, we also found that the photocurrent increased in amplitude with the radiant flux (Supplementary Figure S17) and could be evoked by light pulse as short as 3 ms (Supplementary Figure S18).

Finally, we showed that the photoresponses can be reversibly blocked by the AMPA receptor antagonist DNQX (100 $\mu \mathrm{M})$ but not by the NMDA receptor antagonist AP5 (100 $\mu \mathrm{M})$ (Supplementary Figure S19). This demonstrates that $\mathrm{TCP}_{\text {fast }}$ photocurrents are receptor-specific and that the 
photoswitchable ligands are indeed covalently tethered to the GluRs (as they are not washed away by the competitive antagonists).

\section{$\underline{\text { In vivo photocontrol of neural activity in gerbil's cochlea }}$}

The potential of $\mathrm{TCP}_{\text {fast }}$ to in vivo photosensitize SGNs was tested in the Mongolian gerbil cochlea using the same batch in the same click reaction condition than for in vitro characterization above. To do so, we applied TCP fast to the niche of the round window (RW, i.e. one of the two openings into the cochlea) for passive diffusion into the cochlea and recorded acoustically and optically evoked cochlear mass potentials (Supplementary Figure S20.A $1-4$ ). Following a $10 \mathrm{~min}$ application of $12.5 \mu \mathrm{M} \mathrm{TCP}$ fast $(0.25 \%$ of organic solvent) and wash-out, the acoustically evoked potentials reflecting the outer hair cells (i.e. the cochlear microphonic, Supplementary Figure S20.A 3 and S21.B), inner hair cells (i.e. the summating potential, Supplementary Figure S20.A 4 and S20.C), and the SGNs (i.e. the compound action potential, CAP, Supplementary Figure S20.A 4 and S20.D) remained largely unchanged ( $n=4$, Friedman's test), indicating that $\mathrm{TCP}_{\text {fast }}$ incubation does not interfere with cochlear physiology. Upon subsequent optical fiber-based stimulation (blue laser, $\lambda$ $=473 \mathrm{~nm}$ ), we recorded transient optically evoked CAPs (oCAPs) in 12 out of 12 cochleae treated with TCP fast. OCAPs were similar in shape to acoustically evoked CAP and had an amplitude of 40.88 $\pm 12.58 \mu \mathrm{V}$ (equivalent to the amplitude of a $50 \mathrm{~dB}$ SPL toneburst, Supplementary Figure S20.E). oCAPs vanished within minutes of optical stimulation, which was accompanied of a disappearance of the acoustic potentials reflecting the IHC and SGNs activation. The number of synapses per IHC (i.e. the juxtaposition of pre- [CtBP2] and post-synaptic [Homer 1] markers) was similar between treated and non-treated cochleae, at all frequencies, arguing against glutamate excitotoxicity induced by $\mathrm{TCP}_{\text {fast }}-$ mediated optical stimulation (Supplementary Figure S20.F-G). 


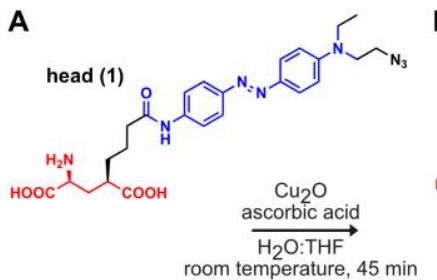

tail (2)

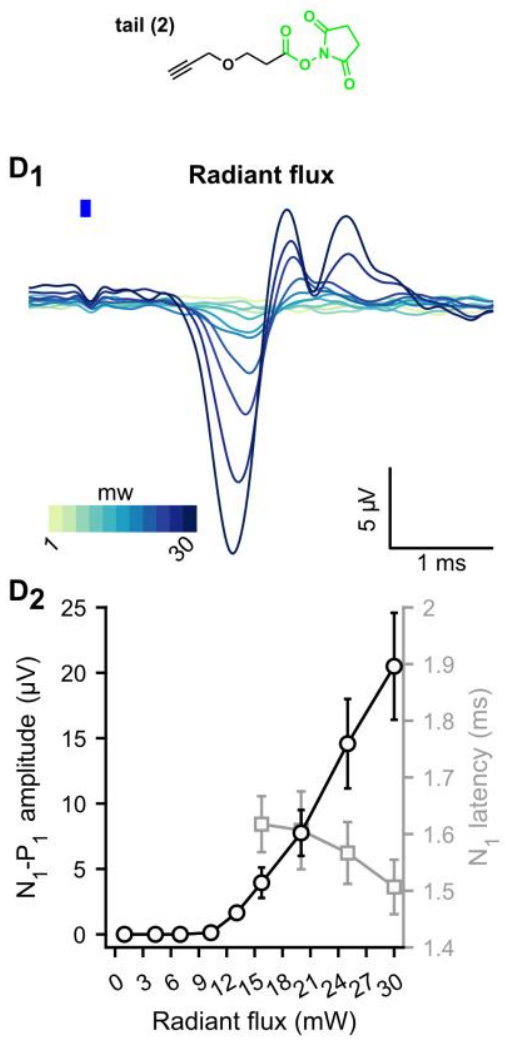

$B_{\text {TCP fast }}(3)$
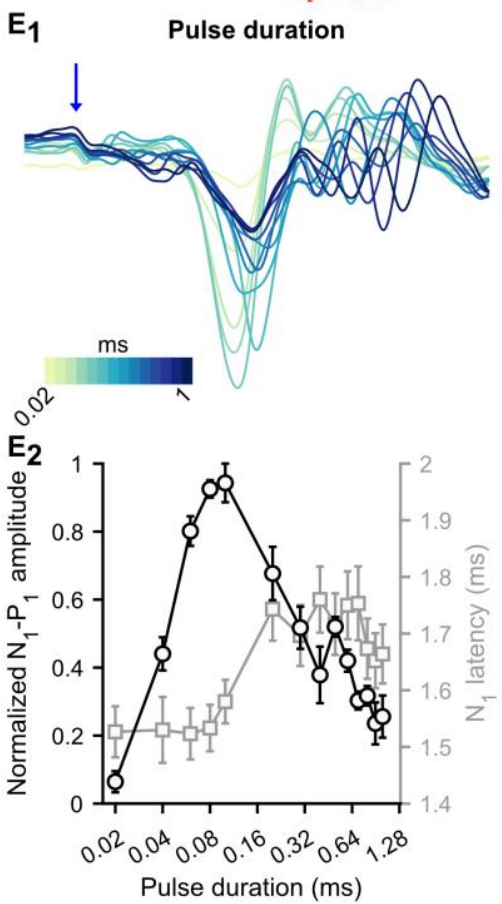

C

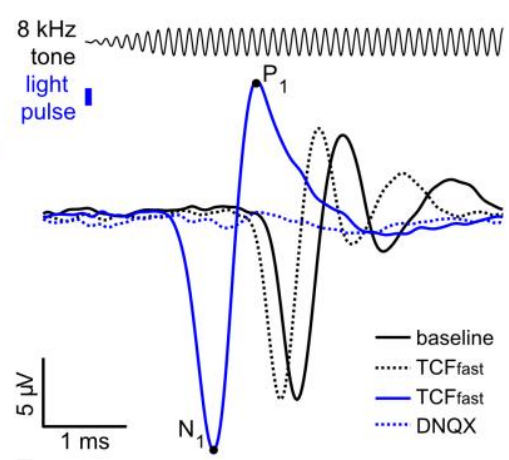

$F_{1}$

I

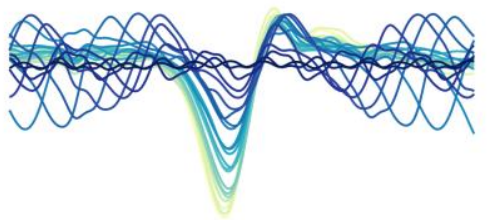

$\mathrm{Hz}$
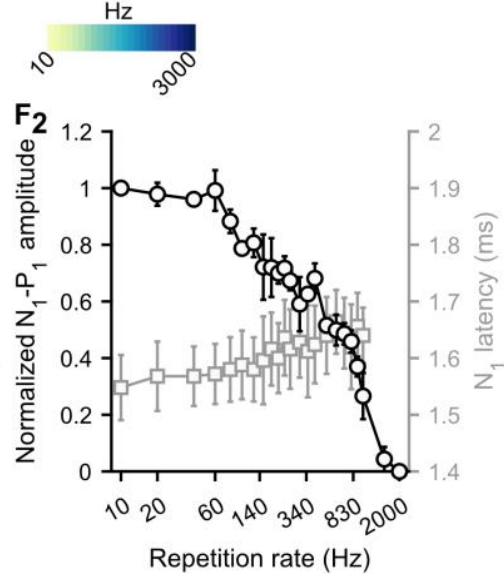

Figure 1. Fast photoswitchable control of SGN activity mediated by TCP fast. A. Molecular design showing 'head' and 'tail' precursors of TCP fast that are freshly coupled prior to incubation in neuronal tissue. B. Photoisomerization between the cis (blue light, $\lambda=460 \mathrm{~nm}$ ) and trans (dark, fast relaxation) conformations. C. Representative acoustically- (black, aCAP) and optically-evoked CAP (blue, oCAP) following $2.5 \mu \mathrm{M}$ application of TCP fast. aCAP (black, 200 averages, $8 \mathrm{kHz}$ toneburst, $30 \mathrm{~dB} \mathrm{SPL}$, repetition rate $=20 \mathrm{~Hz}$ ) are similar before and after TCPfast application. oCAP (blue, $80 \mu \mathrm{s}, 30 \mathrm{~mW}$, repetition rate $=10 \mathrm{~Hz})$ is abolished following application of competitive antagonist DNQX $(1 \mathrm{mM})$. Stimuli are represented on the top. $\mathbf{D}_{1}-\mathbf{F}_{1}$. Representative oCAP in response to various radiant fluxes (80 $\mu \mathrm{s}$ at $10 \mathrm{~Hz}, \mathrm{D}_{1}$ ), pulse durations $\left(27 \mathrm{~mW}\right.$ at $\left.10 \mathrm{~Hz}, \mathrm{E}_{1}\right)$ and repetition rates $\left(80 \mu \mathrm{s}\right.$ at $\left.27 \mathrm{~mW}, \mathrm{~F}_{1}\right)$. In $\mathrm{D}_{1}$ and $\mathrm{F}_{1}$, the blue line indicates the light stimuli and in $E_{1}$ the blue arrow indicates the beginning of the light pulse. A color scale is used to represent the variable. $\mathbf{D}_{2}-\mathbf{F}_{2}$. Quantification ( $n=6$ cochleae) of the oCAP amplitude $\left(\mathrm{N}_{1}-\mathrm{P}_{1}\right.$, black axis) and oCAP latency ( $\mathrm{N}_{1}$, gray axis) as a function of the radiant flux $\left(D_{2}\right)$, the pulse duration $\left(E_{2}\right)$ and the repetition rate $\left(F_{2}\right)$. In $E_{2}$ and $F_{2}$, oCAP amplitudes were expressed as relative to the highest amplitude recorded for the given measure.

Next, we employed a lower $\mathrm{TCP}_{\text {fast }}$ dose $(2.5 \mu \mathrm{M},<0.05 \%$ of organic solvent) which enabled stable acoustically and optically evoked mass potentials in $60 \%$ of the incubated cochleae (Figure 1.C-F, Supplementary Figure S21.A-C. In 30\% of the incubated cochleae, oCAPs could be recorded only transiently and loss of OCAP was accompanied by the light-induced loss of the acoustic potentials that reflect the activation of IHC and SGNs, Supplementary Figure S21.D-F). oCAPs were similar in shape and amplitude to aCAP evoked by a $40 \mathrm{~dB}$ SPL toneburst but consistent with direct neural excitation showed a shorter latency ( 1.5 ms, Figure 1.C). oCAPs could be abolished by 
DNQX (1 mM) application in the RW, confirming a response mediated by AMPA receptors (Figure 1.C, dashed blue trace).

We further characterized the $\mathrm{TCP}_{\text {fast }}$-mediated optical response by measuring oCAP amplitude and latency as a function of radiant flux $(n=6)$ using $80 \mu$ s light pulses at a repetition rate of $10 \mathrm{~Hz}$ (Figure 1.D $\mathrm{D}_{1-2}$ ). oCAP threshold amounted to $12.5 \pm 0.62 \mathrm{~mW}(1 \pm 0.05 \mu \mathrm{J})$. From there, oCAP amplitude increased linearly with radiant flux up to $20.5 \pm 4.09 \mu \mathrm{V}$ at $30 \mathrm{~mW}$ and latency decreased from $1.62 \pm 0.05 \mathrm{~ms}$ to $1.51 \pm 0.05 \mathrm{~ms}$. Next, we measured the effect of the pulse duration on the OCAP (Figure 1. $E_{1-2}, 30 \mathrm{~mW}$, repetition rate $=10 \mathrm{~Hz}$ ): the biggest oCAPs were recorded in response to 80 and $100 \mu$ s light pulse. From there, oCAPs decreased in amplitude for shorter and longer durations. In 50\% of the cases, sizable oCAP (i.e. $>1 \mu \mathrm{V}$ ) were measured in light pulses as short as $20 \mu \mathrm{s}$, corresponding to $0.6 \mu \mathrm{J}$. In response to light pulses shorter than $100 \mu \mathrm{s}$, oCAP were characterized by a single negative wave occurring at $\sim 1.54 \mathrm{~ms}$. In contrast, oCAPs evoked by longer pulse had multiple negative peaks which might reflect the firing of multiple synchronous action potential across SGNs in response to the longer stimuli. Finally, we measured the effect of the repetition rate on oCAPs using $80 \mu$ s light pulses (Figure 1. $F_{1-2}, 30 \mathrm{~mW}$ ). The oCAPs were stable in amplitude up to $60 \mathrm{~Hz}$ and decreased exponentially at higher repetition rate until not being observable above $1.5 \mathrm{kHz}$. For one cochlea for which DNQX (1 mM) application at the RW (Supplementary Figure S22) could be performed, oCAPs were initially observable up to $2 \mathrm{kHz}$ and abolished by the DNQX, supporting the concept of fast control of AMPA receptor with TCP fast in the SGNs.

\section{DISCUSSION}

In this work, we developed a chemical-biological method, called $\mathrm{TCP}_{\text {fast}}$, which allows fast photoswitching of neuronal activity in native neurons. TCP fast is a photoswitchable ligand that is chemically attached to endogenous receptors at the postsynaptic side (Izquierdo-Serra et al, 2016). The molecular design of TCP fast optimized the properties of the bistable photoisomerizable group of former TCPs (Izquierdo-Serra et al, 2016), i.e. thermal relaxation lifetime and absorption wavelength, without altering the ligand and the reactive group. $\mathrm{TCP}_{\text {fast }}$ functions as a molecular prosthesis that bypasses the neurotransmitter-encoded signal by a photonic signal. Photosensitization of cochlear SGNs by locally administered TCP fast enabled temporally precise lightevoked SGN firing up to a rate of $1.5 \mathrm{kHz}$, hence beyond the limits of the fastest optogenetic SGN stimulation ( $\leq 1 \mathrm{kHz}$ (Keppeler et al, 2018)). Hence, TCP fast-mediated photopharmacology might serve as an interesting alternative to the optogenetic approach (Dieter et al, 2020; Kleinlogel et al, 2020) for the development of an optical cochlear implant.

$\mathrm{TCP}_{\text {fast }}$ elicited depolarizing photocurrents that are activated by the cis isomer ('cis-on', which is generally preferred to avoid activation in the dark) and that are reversed in the absence of illumination with a thermal relaxation lifetime of $220 \mathrm{~ms}$ (Supplementary Figure S16). We can currently only speculate on how such thermal relaxation rate yields the ultrafast photostimulation of SGNs eliciting SGN CAPs with interstimulus intervals ranging from few milliseconds to submillisecond. Of note, postsynaptic boutons of SGNs likely contain hundreds of AMPAR such that each light stimulus might hit a sufficient number of AMPARs with the TCP fast being in the trans state. Moreover, CAPs represent population responses and so light pulses might be recruiting variable 
subsets of SGNs. Future work could consider to further speed-up thermal relaxation potentially by replacing the current azobenzene unit in $\mathrm{TCP}_{\text {fast }}$ with faster photoswitches such as (hydroxysubstituted) phenylazopyrimidine (milliseconds to nanoseconds range (Camarero et al, 2020; Čechová et al, 2020; Garcia-Amorós et al, 2012)). However, such accelerated back-switching might in turn result in lower \%cis conversion in the photostationary state and, therefore, require higher light intensity. In addition, further increasing the wavelength for photoswitching (Rullo et al, 2014) might improve the overall utility of the method due to better tissue penetration and lower phototoxicity risk.

We demonstrated, in dissociated hippocampal neurons, specific photomodulation of AMPA/kainate receptors by $\mathrm{TCP}_{\text {fast }}$. In this experimental setting, $\mathrm{TCP}_{\text {fast }}$ photomodulation required presence of glutamate in the bath solution, which we could not avoid at any of the concentration tested (Supplementary Figure S15). One may speculate that the requirement of glutamate could be caused by incomplete conjugation of $\mathrm{TCP}_{\text {fast }}$ to a heterogeneous population of endogenous GluRs. This concept may be translated into a distinctive subunit occupancy resulting in differential agonist affinity and efficacy and so reducing the channel open probability (gating) (Prieto \& Wollmuth, 2010; Reiner \& Isacoff, 2014; Jin et al, 2003). Another possible mechanism would be the presence of native GluR heterotetramers (Greger et al, 2017) with subunits displaying different TCP conjugation and photoswitching properties (Reiner et al, 2014).

Considering the unique properties of $\mathrm{TCP}_{\text {fast }}$ to modulate native GluR activity, $\mathrm{TCP}_{\text {fast }}$ was tested in vivo at the synapse between IHC and SGNs of the cochlea. TCP fast mediated control of the SGNs was obtained in minutes by diffusing (and washing out) the compound into the cochlea. Interestingly, neural responses were observed in response to light pulses with energies between 0.5 and $1 \mu \mathrm{J}$, which is the lower range of the optogenetic approaches applied to the adult gerbil cochlea (CatCh: 1-2 $\mu$, (Wrobel et al, 2018); f-Chrimson : $5 \mu \mathrm{J}$, (Huet et al, 2021). Additionally, maximal oCAP responses were obtained in response to light pulse as short as $80 \mu \mathrm{s}$, which is substantially shorter than reported for optogenetic tools in the cochlea (Keppeler et al, 2018; Wrobel et al, 2018; Mager et al, 2018; Bali et al, 2021). Finally, $\mathrm{TCP}_{\text {fast }}$ enabled neural responses up to stimulation rate of $1.5 \mathrm{kHz}$. While this observation should be confirmed by single SGNs recording, it is interesting to note that this performance exceeds that obtained with the fastest opsins to date (Chronos: (Keppeler et al, 2018); vf-Chrimson: (Bali et al, 2021) while presenting lower activation threshold (TCP fast $\sim 1 \mu \mathrm{J}$, Chronos-ES/TS and vf-Chrimson-ES/TS $\sim 6 \mu \mathrm{J})$.

$\mathrm{TCP}_{\text {fast }}$ provides similar or better performance than current optogenetic approaches in terms of speed and light requirements, while avoiding the gene therapy required to optogenetically modify SGNs. Yet, long-term availability, efficacy and safety of $\mathrm{TCP}_{\text {fast }}$ or more advanced photoswitches will need to be established. Moreover, neural degeneration often starts with the loss of postsynaptic structures (Kujawa \& Liberman, 2009; Sergeyenko et al, 2013) limiting the utility of $\mathrm{TCP}_{\text {fast }}$ photopharmacology for optical cochlear implants. Future studies should focus on designing safe compound targeting channels expressed at the surface of the surviving SGN somas, while showing similar target specificity, fast kinetics and longer wavelength. This way, photopharmacology might establish a toolkit for photosensitization tailored to the specific neural status of the cochlea or other structures. In addition, a drug-based approach would appeal patients and the pharmaceutical industry and facilitate regulatory processes. Photopharmacology has 
previously demonstrated its potential in photosensitization of other sensory systems like the retina (Marc et al, 2014; Izquierdo-Serra et al, 2016; Tochitsky et al, 2017; Yue et al, 2016). To the best of our knowledge, this is the first proof-of-concept photopharmacology study in the auditory system and opens an avenue for auditory research and clinical applications such as in optical cochlear implants designed to fundamentally improve hearing restoration.

\section{ONLINE METHODS}

Click reaction. To a $1.5 \mathrm{ml}$ glass vial containing azide 1 ('head', $1.00 \mathrm{mg}, 1 \mathrm{eq}$ ) and copper(I) oxide $(0.82 \mathrm{mg}, 3 \mathrm{eq})$ in tetrahydrofuran $(47 \mu \mathrm{l})$ and equipped with a magnetic stir bar was added a solution of ascorbic acid (1.34 mg, $4 \mathrm{eq})$ in water $(94 \mu \mathrm{l})$ and the resulting mixture was vortexed for $1 \mathrm{~min}$. Then, a solution of alkyne 2 ('tail', $0.47 \mathrm{mg}, 1.1 \mathrm{eq}$ ) in tetrahydrofuran ( $47 \mu \mathrm{l}$ ) was added and the resulting mixture was stirred at room temperature for $45 \mathrm{~min}$. The so-obtained final mixture was taken up in dimethylsulfoxide $(193 \mu \mathrm{l})$, vortexed, centrifuged for $1 \mathrm{~min}$ to separate the insoluble copper(I) oxide particles, and finally divided into aliquots of the final compound stock solution (Supplementary Scheme S2).

Alternatively, the click reaction could be performed in an Eppendorf tube and stirred with a suitable mixer.

We observed that the catalytic performance of the copper(I) oxide may vary significantly from batch to batch, therefore the actual reaction time should be adjusted to obtain at least a $95 \%$ conversion of the starting material and a $\left(\mathrm{TCP}_{\text {fast }}\right)$ :(hydrolyzed $\mathrm{TCP}_{\text {fast }}$ ) ratio greater than 3 (Supplementary Figure S9). In vitro and in vivo biological characterizations were done using the same batch and results were reproducible across experiments.

Rat hippocampal neural primary culture. All experiments were done in compliance with the national animal care guidelines and were approved by the board for animal welfare of the University Medical Center Goettingen and the animal welfare office of the state of Lower Saxony.

Primary hippocampal cultures were prepared from newborn P0-P3 pups Wistar rats. Brains were collected in a 10-cm petri dish containing ice-cold dissection media (HBSS (Gibco) + $10 \mathrm{mM}$ Hepes (Gibco)). Hippocampi were separated from the brain, and meninges were removed. Hippocampi were digested with $2 \mathrm{ml}$ pre-warmed $37^{\circ} \mathrm{C} 0.1 \%$ trypsin-EDTA (Gibco, Germany) for 20 min at $37^{\circ} \mathrm{C}$. Trypsin was removed, and the tissue was washed three times with dissection medium. Dissection medium was replaced with $1 \mathrm{ml}$ pre-warmed complete DMEM (DMEM with 1X Gluta- max, 10\% FCS/FBS and $1 \%$ penicillin $(100 \mathrm{U} / \mathrm{ml}) /$ streptomycin $(100 \mu \mathrm{g} / \mathrm{ml})$; all from Gibco). Tissue was triturated by gentle pipetting. The tissue suspension was filtered through a 100- $\mu \mathrm{m}$ cell strainer (BD Biosciences).

Cells were counted using the trypan blue exclusion method and cultured on 12-mm glass coverslips (Thermo Scientific) coated with poly-D-lysine (PDL, Sigma). Neurons were plated in 24-well plates at a density of 50,000 hippocampal neurons per coverslip in $500 \mu \mathrm{l}$ of NB+ medium (Neurobasal with $2 \%$ B-27 supplement, $1 \%$ Glutamax and $1 \%$ penicillin $(100 \mathrm{U} / \mathrm{ml}) /$ streptomycin $(100 \mu \mathrm{g} / \mathrm{ml})$; all from Gibco) at $37^{\circ} \mathrm{C}$ and $5 \% \mathrm{CO}$. Half of the medium in each well was changed every 3-4 days. 
Electrophysiology recording conditions for rat hippocampal neurons. Before starting the recording, neurons between 10 to 18 days in vitro (div) were incubated with $\mathrm{TCP}_{\text {fast }}$ at concentrations: $25-50-75-100 \mu \mathrm{M}(\leq 2 \%$ DMSO) for $2 \mathrm{~min}$, in the absence of light and in $\mathrm{pH} 9$ bath solution composed by (in $\mathrm{mM}$ ): $100 \mathrm{NaCl}, 1 \mathrm{MgCl}_{2}, 2.5 \mathrm{KCl}, 2.5 \mathrm{CaCl}_{2}, 10$ glucose and 50 sodiumcarbonate/sodiumbicarbonate, $310 \mathrm{mOsm} / \mathrm{kg}, \mathrm{pH} 9$ adjusted with $\mathrm{NaOH}$. NMDG incubation solution at $\mathrm{pH} 9$ is composed by (in $\mathrm{mM}$ ): $100 \mathrm{NMDG}, 2 \mathrm{MgCl}_{2}, 2.5 \mathrm{KCl}, 10$ glucose and 50 sodiumcarbonate/sodiumbicarbonate, $310 \mathrm{mOsm} / \mathrm{kg}$, $\mathrm{pH} 9$ adjusted with $\mathrm{KOH}$.

Voltage and current-clamp recordings under whole-cell configuration were done using an Axopatch 200B amplifier, filtered at $5 \mathrm{kHz}$, digitized with an Axon DigiData 1440A interface (Axon Instruments). Acquisition software used was Clampex 10.5.2.6 (Axon Instruments).

Light stimulation was performed at saturating radiant flux (5-14 $\mathrm{mW})$ using diode-pumped solidstate lasers $(\lambda=473 \mathrm{~nm})$ focused into a $400-\mu \mathrm{m}$ optic fiber. Light pulses were applied by a fast computer-controlled shutter (Uniblitz LS6ZM2, Vincent Associates, Rochester, USA). Radiant flux was adjusted by placement of density filters between the laser output and the optic fiber.

During recordings, neurons were maintained at room temperature (r.t., $25-27^{\circ} \mathrm{C}$ ) in a continuous perfusion of bath solution and clamped at $-70 \mathrm{mV}$. Bath solution was composed of (in $\mathrm{mM}$ ): 140 $\mathrm{NaCl}, 1 \mathrm{MgCl}_{2}, 2.5 \mathrm{KCl}, 10 \mathrm{HEPES}, 2.5 \mathrm{CaCl}_{2}$ and $10-20 \mathrm{mM}$ glucose to fix osmolarity to $310 \mathrm{mOsm} / \mathrm{kg}$, $\mathrm{pH} 7.42$ adjusted with $\mathrm{NaOH}$. Borosilicate glass pipettes were pulled with a typical resistance of 3$8 \mathrm{M} \Omega$ for neurons. Pipette solution contained (in $\mathrm{mM}$ ): 129 potassium gluconate, $10 \mathrm{HEPES}, 10 \mathrm{KCl}$, $4 \mathrm{MgATP}$ and $0.3 \mathrm{Na}_{3} \mathrm{GTP}$. Osmolarity is adjusted at $289 \mathrm{mOsm} / \mathrm{kg}$ and $\mathrm{pH} 7.2$ adjusted with $\mathrm{KOH}$.

Drug preparation for in vivo cochlea infusion. Artificial perilymph solution consisted of the following (in $\mathrm{mM}$ ): $137 \mathrm{NaCl} ; 5 \mathrm{KCl} ; 2 \mathrm{CaCl}_{2} ; 1 \mathrm{MgCl}_{2} ; 1 \mathrm{NaHCO}_{3} ; 11$ glucose; pH 7.4 adjusted with $\mathrm{NaOH}$; osmolarity: $304 \pm 4.3 \mathrm{mOsm} / \mathrm{kg}$. Before each experiment, $\mathrm{TCP}_{\text {fast }}$ was diluted in artificial perilymph to a final concentration ranging from 2.5 to $12.5 \mu \mathrm{M}$.

Animal preparation for cochlear potentials recordings and cochlear pharmacology. All experiments were done in compliance with the German national animal care guidelines and were approved by the board for animal welfare of the University Medical Center Göttingen and the animal welfare office of the state of Lower Saxony (agreement 2014/1726 and 2019/3188). Experiments were performed on adult ( $>8$ weeks old) Mongolian gerbils (Meriones unguicalatus) of both sexes.

Gerbils were anesthetized by isoflurane (5\% for anesthesia induction, 1-2\% for maintenance, frequent testing for the absence of hind-limb withdrawal reflex) and analgesia was obtained by subdermal injection of buprenorphine $(0.1 \mathrm{mg} / \mathrm{kg}$ body weight) and carprofen $(5 \mathrm{mg} / \mathrm{kg}$ body weight). Body temperature was maintained at $37^{\circ} \mathrm{C}$ using a custom-designed heat plate. The cochlea was exposed following a retro-auricular approach and a bullostomy. The recording electrode was placed against the bony edge next to the round window (RW) leaving enough space to access the RW for pharmacological manipulation and optical stimulation. The pharmacological manipulation was made by filling the RW niche with the solution of interest. The RW membrane was punctured to increase the fluid exchange between the cochlea and RW niche. Between each solution, the RW niche was emptied by capillarity. The artificial perilymph solution had the following 
composition (in $\mathrm{mM}$ ): $137 \mathrm{NaCl}, 5 \mathrm{KCl}, 2 \mathrm{CaCl} 2,1 \mathrm{MgCl} 2,1 \mathrm{NaHCO}, 11$ glucose. The pH was 7.3 and osmolarity maintained at $300 \mathrm{mOsm} / \mathrm{kg} \mathrm{H} 2 \mathrm{O}$.

Acoustically evoked cochlear potentials. Acoustical cochlear potentials were obtained in response to $8 \mathrm{kHz}$ tone burst (pulse duration $=8 \mathrm{~ms}$, rise/fall time $=1 \mathrm{~ms}$, repetition rate $=20 \mathrm{~Hz}$, level: 20 to $80 \mathrm{~dB}$ SPL per $10 \mathrm{~dB}$ step, 200 repetitions per level). The mass potentials were amplified using a custom-made physiological amplifier and sampled at a rate of $50 \mathrm{kHz}(\mathrm{NI} \mathrm{PCl}-6229$, National Instrument). Stimulus generation and data acquisition were made using a custom-written software (MATLAB, MathWorks) employing National Instrument data acquisition cards in association with custom-build acoustic and laser-controller.

The cochlear microphonic was extracted by averaging the band-pass filtered (cut-off frequencies = 5.6 and $11.1 \mathrm{kHz}$ ) mass potential recorded using the RW electrode and its amplitude defined as the RMS value. The CAP and summating potentials were obtained by averaging the low-pass filtered (cut-off frequency $=3.5 \mathrm{kHz}$ ) mass-potential. The CAP amplitude was defined as the amplitude between the first negative peak $\left(N_{1}\right)$ and the following positive peak $\left(P_{1}\right)$. The summating potential amplitude was defined as the difference between the plateau response (between 5 and $7 \mathrm{~ms}$ ) and the baseline prior to the stimulation onset.

Optically evoked cochlear potentials. Optical cochlear potentials were obtained in response to blue light pulse delivered by a $200 \mu \mathrm{m}$ optical fiber coupled to a $473 \mathrm{~nm}$ laser (MLL-FN-473-100, $100 \mathrm{~mW}$, diode pumped solid state [DPSS]; Changchun New Industry Optoelectronics). Irradiance was calibrated with a laser power meter (LaserCheck; Coherent Inc.) The CAP was obtained was described above.

Inner hair cell synapse counting. Cochleae were fixated in $4 \%$ formaldehyde for about 15 min, after which, they were decalcified in $0.12 \mathrm{M}$ EDTA solution for about 12 hours (at $4^{\circ} \mathrm{C}$ ). Organs of Corti were then: (i) isolated in phosphate buffer saline (PBS); (ii) incubated for an hour in Goat serum dilution buffer (GSDB, comprised of: $16 \%$ normal goat serum, $450 \mathrm{mM} \mathrm{NaCl}, 0.3 \%$ Triton X-100, 20 $\mathrm{mM}$ phosphate buffer, $\mathrm{pH} 7.4$ ); (iii) treated for 2 hours with the primary antibodies: mouse antiCtBP2 (BD Biosciences, 1:200), rabbit anti-myo6 (Proteus Biosciences, 1:200), chicken anti-Homer1 (SYSY, 1:200) for staining postsynapse, inner hair cells and presynapse, respectively. After washing the primary antibodies with PBS for $20 \mathrm{~min}$, the secondary antibodies were incubated: Goat-antiChicken 488 (Invitrogen, 1:500), Goat-anti-Rabbit 568 (Thermo Fisher, 1:500), Goat-anti-Mouse 647 (Invitrogen, 1:500). After another washing step with PBS, samples were mounted on a glass slide in Mowiol (Carl Roth) mounting medium. Confocal images of the organ of Corti were first obtained using a 10x magnification (LSM 510 microscope, Carl Zeiss, Jena) in order to fit a Greenwood function (Greenwood, 1961; Müller, 1996) to them and localize the tonotopic position of the inner hair cells. The synapses were visualized at 0.5, 1, 2, 4, 8, 16 and $32 \mathrm{kHz}$ using a 100x magnification (Abberior Instruments Expert Line STED microscope) and counted using the spot function from Imaris software (version 7.6.5).

Data analysis and statistics. Amplitude of photocurrents were analyzed using IgorPro (Wavemetrics). Displayed whole-cell current traces have been filtered using the infinite impulse response digital filter from IgorPro (low-pass filter with cutoff of $50 \mathrm{~Hz}$ ). The drift in current was corrected where appropriate with the IgorPro (WaveMetrics) software using a custom-made macro 
for drift correction. Statistics were done with OriginPro 8.5 (OriginLab) and Matlab (Mathworks). In vivo electrophysiological data were analyzed using custom-made Matlab routines.

\section{ACKNOWLEDGEMENTS}

This research received funding from the European Union Research and Innovation Programme Horizon 2020 - Human Brain Project SG3 (945539), DEEPER (ICT-36-2020-101016787), Agency for Management of University and Research Grants/Generalitat de Catalunya (CERCA Programme; 2017-SGR-1442 project), Fonds Européen de Développement Économique et Régional (FEDER) funds, Ministry of Science and Innovation (Grant PID2019-111493RB-I00), Fundaluce and "la Caixa" foundations (ID 100010434, agreement LCF/PR/HR19/52160010). The project Clúster Emergent del Cervell Humà ( $\mathrm{CECH}, 001-\mathrm{P}-001682$ ) is co-financed by the European Union Regional Development Fund within the framework of the ERDF Operational Program of Catalonia 2014-2020 with a grant of 50\% of total eligible cost. A.G.-C. was supported by fellowship BES-2014-068169.

We thank Christiane Senger-Freitag, Sandra Gerke and Sina Langer for technical support, Gerhard Hoch for his expert technical support and Patricia Räke-Kügler for excellent administrative support. We thank Thomas Mager for providing the patch clamp setup. This work was funded by the European Research Council through the Advanced Grant "OptoHear" to TM under the European Union's Horizon 2020 Research and Innovation program (grant agreement No. 670759), the Fraunhofer and Max-Planck Cooperation Program (NeurOpto grant) to TM, was further supported by the German Research Foundation through the Priority Program 1926 "Next generation optogenetics" to $\mathrm{AH}$ and TM, the Leibniz Program (to TM) and the Deutsche Forschungsgemeinschaft (DFG, German Research Foundation) under Germany's Excellence Strategy - EXC 2067/1-390729940 to AH and TM. In addition, this research is supported by Fondation Pour I'Audition (FPA RD-2020-10).

We thank Dr. Vladimir Belov, Jurgen Bienert and Jan Seikowski for HPLC and LC-MS measurements of final TCP fast products.

\section{AUTHOR CONTRIBUTIONS}

AGC, AH, CM, AL, TM and PG designed the study. CM synthesised and analysed all compounds. AGC did electrophysiology in cultured neurons. AH did in vivo measurements in adult gerbils. AT did immunohistochemistry and image analysis. AL supervised the chemical synthesis. All authors contributed to the analysis of data and preparation of the article.

\section{COMPETING INTERESTS}

TM is a co-founder and CEO of OptoGenTech company. The other authors declare no conflict of interests.

\section{REFERENCES}


Ankenbruck N, Courtney T, Naro Y \& Deiters A (2018) Optochemical Control of Biological Processes in Cells and Animals. Angew Chem - Int Ed 57: 2768-2798

Bali B, Lopez de la Morena D, Mittring A, Mager T, Rankovic V, Huet AT \& Moser T (2021) Utility of red-light ultrafast optogenetic stimulation of the auditory pathway. EMBO Mol Med

Bandara HMD \& Burdette SC (2012) Photoisomerization in different classes of azobenzene. Chem Soc Rev 41: 1809-1825

Berlin S, Szobota S, Reiner A, Carroll EC, Kienzler MA, Guyon A, Xiao T, Trauner D \& Isacoff EY (2016) A family of photoswitchable NMDA receptors. eLife: 1-29

Camarero N, Trapero A, Pérez-Jiménez A, Macia E, Gomila-Juaneda A, Martín-Quirós A, Nevola L, Llobet A, Llebaria A, Hernando J, et al (2020) Photoswitchable dynasore analogs to control endocytosis with light. Chem Sci 11: 8981-8988

Čechová L, Filo J, Dračínský M, Slavov C, Sun D, Janeba Z, Slanina T, Wachtveitl J, Procházková E \& Cigáň M (2020) Polysubstituted 5-Phenylazopyrimidines: Extremely Fast Non-ionic Photochromic Oscillators. Angew Chem - Int Ed 59: 15590-15594

Chi L, Sadovski O \& Woolley GA (2006) A blue-green absorbing cross-linker for rapid photoswitching of peptide helix content. Bioconjug Chem 17: 670-676

Dieter A, Keppeler D \& Moser T (2020) Towards the optical cochlear implant: optogenetic approaches for hearing restoration. EMBO Mol Med n/a: e11618

Garcia-Amorós J, Díaz-Lobo M, Nonell S \& Velasco D (2012) Fastest Thermal Isomerization of an Azobenzene for Nanosecond Photoswitching Applications under Physiological Conditions. Angew Chem 124: 12992-12995

Gorostiza P \& Isacoff E (2007) Optical switches and triggers for the manipulation of ion channels and pores. Mol Biosyst 3: 686-704

Gorostiza P \& Isacoff EY (2008) Optical Switches for Remote and Noninvasive Control of Cell Signaling. Science 322: 395-399

Gorostiza P, Volgraf M, Numano R, Szobota S, Trauner D \& Isacoff EY (2007) Mechanisms of photoswitch conjugation and light activation of an ionotropic glutamate receptor. Proc Natl Acad Sci U S A 104: 10865-70

Greenwood DD (1961) Critical Bandwidth and the Frequency Coordinates of the Basilar Membrane. J Acoust Soc Am 33: 1344-1356

Greger IH, Watson JF \& Cull-Candy SG (2017) Structural and Functional Architecture of AMPA-Type Glutamate Receptors and Their Auxiliary Proteins. Neuron 94: 713-730 
Grothe B, Pecka M \& McAlpine D (2010) Mechanisms of Sound Localization in Mammals. Physiol Rev 90: 983-1012

Harvey JH \& Trauner D (2008) Regulating Enzymatic Activity with a Photoswitchable Affinity Label. Chembiochem 9: 191-193

Hu H, Gan J \& Jonas P (2014) Fast-spiking, parvalbumin+ GABAergic interneurons: From cellular design to microcircuit function. Science 345

Huet A, Batrel C, Tang Y, Desmadryl G, Wang J, Puel JL \& Bourien J (2016) Sound coding in the auditory nerve of gerbils. Hear Res 338: 32-39

Huet AT, Dombrowski T, Rankovic V, Thirumalai A \& Moser T (2021) Developing Fast, Red-Light Optogenetic Stimulation of Spiral Ganglion Neurons for Future Optical Cochlear Implants. Front Mol Neurosci 14: 635897

Hüll K, Morstein J \& Trauner D (2018) In Vivo Photopharmacology. Chem Rev 118: 10710-10747

Izquierdo-Serra M, Bautista-Barrufet A, Trapero A, Garrido-Charles A, Díaz-Tahoces A, Camarero N, Pittolo S, Valbuena S, Pérez-Jiménez A, Gay M, et al (2016) Optical control of endogenous receptors and cellular excitability using targeted covalent photoswitches. Nat Commun 7: 12221

Jin R, Banke TG, Mayer ML, Traynelis SF \& Gouaux E (2003) Structural basis for partial agonist action at ionotropic glutamate receptors. Nat Neurosci 6: 803-810

Kaczmarek LK \& Zhang Y (2017) Kv3 Channels: Enablers of Rapid Firing, Neurotransmitter Release, and Neuronal Endurance. Physiol Rev 97: 1431-1468

Keppeler D, Martins Merino R, Lopez de la Morena D, Bali B, Tarquin Huet A, Gehrt A, Wrobel C, Subramanian S, Dombrowski T, Rankovic V, et al (2018) Ultrafast optogenetic stimulation of the auditory pathway by targeting-optimized Chronos. EMBO J 37: e99649

Kienzler MA \& Isacoff EY (2017) Precise modulation of neuronal activity with synthetic photoswitchable ligands. Curr Opin Neurobiol

Kienzler MA, Reiner A, Trautman E, Yoo S, Trauner D \& Isacoff EY (2013) A red-shifted, fast-relaxing azobenzene photoswitch for visible light control of an ionotropic glutamate receptor. J Am Chem Soc 135: 17683-17686

Kleinlogel S, Vogl C, Jeschke M, Neef J \& Moser T (2020) Emerging approaches for restoration of hearing and vision. Physiol Rev

Kujawa SG \& Liberman MC (2009) Adding insult to injury: cochlear nerve degeneration after "temporary" noise-induced hearing loss. J Neurosci 29: 14077 
Mager T, Lopez de la Morena D, Senn V, Schlotte J, D'Errico A, Feldbauer K, Wrobel C, Jung S, Bodensiek K, Rankovic V, et al (2018) High frequency neural spiking and auditory signaling by ultrafast red-shifted optogenetics. Nat Commun 9: 1750

Marc R, Pfeiffer R \& Jones B (2014) Retinal prosthetics, optogenetics, and chemical photoswitches. ACS Chem Neurosci 5: 895-901

Moser T, Grabner CP \& Schmitz F (2019) Sensory processing at ribbon synapses in the retina and the cochlea. Physiol Rev 100: 103-144

Müller M (1996) The cochlear place-frequency map of the adult and developing mongolian gerbil. Hear Res 94: 148-156

Prieto ML \& Wollmuth LP (2010) Gating modes in AMPA receptors. J Neurosci 30: 4449-4459

Reiner A \& Isacoff EY (2014) Tethered ligands reveal glutamate receptor desensitization depends on subunit occupancy. Nat Chem Biol: 1-10

Rullo a, Reiner A, Reiter A, Trauner D, Isacoff EY \& Woolley G a (2014) Long wavelength optical control of glutamate receptor ion channels using a tetra-ortho-substituted azobenzene derivative. Chem Commun 50: 14613-14615

Sergeyenko Y, Lall K, Liberman MC \& Kujawa SG (2013) Age-related cochlear synaptopathy: an earlyonset contributor to auditory functional decline. J Neurosci 33: 13686-13694

Shao C, Wang X, Xu J, Zhao J, Zhang Q \& Hu Y (2010) Carboxylic acid-promoted copper(I)-catalyzed azide-alkyne cycloaddition. J Org Chem 75: 7002-7005

Shao C, Zhu R, Luo S, Zhang Q, Wang X \& Hu Y (2011) Copper(I) oxide and benzoic acid 'on water': A highly practical and efficient catalytic system for copper(I)-catalyzed azide-alkyne cycloaddition. Tetrahedron Lett 52: 3782-3785

Tochitsky I, Kienzler MA, Isacoff E, Kramer RH \& Kirby F (2017) Restoring Vision to the Blind with Chemical Photoswitches.

Volgraf M, Gorostiza P, Numano R, Kramer RH, Isacoff EY \& Trauner D (2006) Allosteric control of an ionotropic glutamate receptor with an optical switch. Nat Chem Biol 2: 47-52

Wrobel C, Dieter A, Huet A, Keppeler D, Duque-Afonso CJ, Vogl C, Hoch G, Jeschke M \& Moser T (2018) Optogenetic stimulation of cochlear neurons activates the auditory pathway and restores auditory-driven behavior in deaf adult gerbils. Sci Transl Med 10

Yue L, Weiland JD, Roska B \& Humayun MS (2016) Retinal stimulation strategies to restore vision: Fundamentals and systems. Prog Retin Eye Res

Zeng FG (2017) Challenges in Improving Cochlear Implant Performance and Accessibility. IEEE Trans Biomed Eng 64: 1662-1664 


\section{Table of Contents}

\section{General methods and materials for chemical synthesis and characterization}

Supplementary Scheme S1. Chemical synthesis of the 'head' module (compound 1).

\section{Synthetic protocols for the preparation of the 'head' module}

\section{Supplementary Figures (NMR, HPLC-PDA-MS, HRMS, UV-Vis)}

Supplementary Figure S1. NMR spectra of compound $\mathbf{5}$.

Supplementary Figure S2. NMR spectra of compound 7.

Supplementary Figure S3. NMR spectra of compound 8.

Supplementary Figure S4. NMR spectra of compound 9.

Supplementary Figure S5. NMR spectra of compound $\mathbf{1}$ (continued to the next page).

Supplementary Figure S5. NMR spectra of compound 1 (continued from the previous page).

Supplementary Figure S6. HPLC chromatogram of compound 1.

Supplementary Figure S7. High-resolution mass spectrum of compound 1.

Supplementary Figure S8. UV-Vis absorption spectrum of compound $\mathbf{1}$ (trans isomer) in PBS buffer at $\mathrm{pH} 7.4$.

\section{Synthetic protocol for the preparation of $\mathrm{TCP}_{\text {fast }}$}

Supplementary Scheme S2. Preparation of TCP fast via Cu(I)-catalyzed azide-alkyne 1,3-dipolar cycloaddition ("click") reaction.

Supplementary Figure S9. Analysis of the initial and final mixture of a representative "click" reaction for the preparation of $\mathbf{T C P} \mathbf{P}_{\text {fast }}(\mathbf{3})$

Supplementary Figure S10. High-resolution mass spectrum of $\mathrm{TCP}_{\text {fast }}(\mathbf{3})$.

\section{Characterization of TCP fast, lysine-adduct, and side-product by LC-MS}

Supplementary Scheme $\mathbf{S 3}$. Generation and structure of the TCP fast-lysine adduct $(\mathbf{X})$ and detected main sideproduct $(\mathbf{Y})$.

Supplementary Table S1. Calculated mass-to-charge $(\mathrm{m} / \mathrm{z})$ ratio for compounds $\mathbf{1}, \mathrm{TCP}$ fast $(\mathbf{3}), \mathbf{X}, \mathbf{Y}$.

Supplementary Figure S11. LC-MS analysis of the final mixture for the reaction illustrated in Scheme S3 (arbitrary case). Supplementary Figure $\mathbf{S 1 2}$. High-resolution mass spectrum of the $\mathrm{TCP}_{\text {fast }}-$ lysine adduct $(\mathbf{X})$.

\section{Characterization of $\mathrm{TCP}_{\text {fast }}$ in cultured neurons}

Supplementary Figure S13. $\mathrm{TCP}_{\text {fast }}$ conjugation produces photocurrents in untransfected hippocampal neurons in the presence of glutamate.

Supplementary Figure S14. Light stimulation does not affect neuronal responses prior to TCP $_{\text {fast }}$ incubation. Supplementary Figure S15. Optimization of $\mathrm{TCP}_{\text {fast }}$ conjugation conditions to endogenous neural receptors in vitro.

Supplementary Figure S16. Fast relaxation lifetime of $\mathrm{TCP}_{\text {fast }}$ enables single wavelength control of photocurrents in hippocampal neurons.

Supplementary Figure S17. Photocurrent amplitude depends on light intensity. 
Supplementary Figure S18. Neurons incubated with $\mathrm{TCP}_{\text {fast }}$ display reversible cis-on photocurrents in response to blue light pulses as short as a few milliseconds.

Supplementary Figure S19. $\mathrm{TCP}_{\text {fast }}$ photocurrents in neurons are mediated by endogenous non-NMDA glutamate receptors.

\section{In vivo photocontrol of neural activity in gerbil's cochlea}

Supplementary Figure S20. $12.5 \mu \mathrm{M} \mathrm{TCP}$ fast administration into the cochlea enables a transient optically evoked response of the SGNs followed by a loss of function of the inner hair cells and spiral ganglion neurons.

Supplementary Figure S21. In $60 \%$ of the case $2.5 \mu \mathrm{M}$ TCPfast application into the cochlea allows stable photoresponse in absence of toxicity for the organ of Corti.

Supplementary Figure S22. TCP fast enables AMPA-mediated oCAPs up to stimulation rate of $2 \mathrm{kHz}$.

\section{Supplementary references}




\section{General methods and materials for chemical synthesis and characterization}

All chemicals and solvents are from commercial suppliers and used without purification. All reactions were performed under inert atmosphere of argon. All analytical data of photoisomerizable compounds are given for the trans isomer unless otherwise stated. Reactions were monitored by thin layer chromatography (TLC: EMD/Millipore, silica gel 60 on aluminum support, layer thickness: $200 \mu \mathrm{m}$, particle size: 10-12 $\mu \mathrm{m}$ ) by visualization under 254 and/or $365 \mathrm{~nm}$ lamp. Flash column chromatography: Panreac Silica Gel 60, 40-63 $\mu \mathrm{m}$ RE. NMR equipment and methods: VarianMercury $400 \mathrm{MHz} \&$ Varian VNMRS $500 \mathrm{MHz}$. Chemical shifts $(\delta)$ are reported in parts per million (ppm) against the reference compound tetramethylsilane using the signal of the residual nondeuterated solvent [Chloroform- $d \delta=7.26 \mathrm{ppm}(1 \mathrm{H}), \delta=77.16 \mathrm{ppm}\left(13 \mathrm{C}\right.$ ); Dimethylsulfoxide- $d_{6} \delta$ $=2.50 \mathrm{ppm}(1 \mathrm{H}), \delta=39.52 \mathrm{ppm}(13 \mathrm{C}) ;$ Methanol- $\left.d_{4} \delta=3.31 \mathrm{ppm}(1 \mathrm{H}), \delta=49.00 \mathrm{ppm}(13 \mathrm{C})\right]$. HPLCPDA-MS equipment and methods: Waters Alliance 2695 separation module coupled to a Waters 2996 photodiode detector (PDA) and a Waters ACQUITY QDa detector (single quadrupole; electrospray ionization), with the MassLynx software for data acquisition; SunFire C18 Column (100 $\AA$, $5 \mu \mathrm{m}, 4.6 \mathrm{~mm} \times 150 \mathrm{~mm}$ ); injection volume: $5 \mu \mathrm{L}$; mobile phase: water $\mathrm{w} / 0.1 \%$ formic acid (solvent A) and acetonitrile $\mathrm{w} / 0.1 \%$ formic acid (solvent $B$ ); elution method: flow $1 \mathrm{~mL} / \mathrm{min}$, gradient 0.0-1.0 $\min , 5 \% \mathrm{~B} ; 1.0-7.0 \mathrm{~min}, 5-100 \% \mathrm{~B} ; 7.0-8.0 \mathrm{~min}, 100 \% \mathrm{~B} ; 8.0-10.0 \mathrm{~min}, 100-5 \% \mathrm{~B}$; runtime $10 \mathrm{~min}$. Waters Alliance 2795 separation module coupled to a Waters 2996 photodiode detector (PDA) and a Waters 3100 Mass Detector (single quadrupole; electrospray ionization), with the MassLynx software for data acquisition; XSelect CSH C18 Column (130 ̊, $3.5 \mu \mathrm{m}, 4.6 \mathrm{~mm}$ X $50 \mathrm{~mm}$ ); injection volume: $5 \mu \mathrm{L}$; mobile phase: water $w / 0.1 \%$ formic acid (solvent $A$ ) and acetonitrile $w / 0.1 \%$ formic acid (solvent B); elution method: flow $1.6 \mathrm{~mL} / \mathrm{min}$, gradient 0.0-3.5 min, 5-100\% B; 3.5-4.5 min, $100 \%$ B; 4.5-5.0 min, 100-5\% B; runtime $5 \mathrm{~min}$. Spectra have been scanned between 200 and 800 Da with values every 0.1 seconds and peaks are given as mass/charge $(\mathrm{m} / \mathrm{z})$ ratio. Melting points of solid substances were determined on a Büchi melting point M-565 apparatus and are uncorrected. Optical rotations were measured with a Jasco P-2000 polarimeter operating on a sodium D-line (589 $\mathrm{nm}$ ) at $25{ }^{\circ} \mathrm{C}$, using a $10-\mathrm{cm}$ path-length cell. High resolution mass spectrometry analyses were performed with a LTQ-FT Ultra Mass Spectrometer (Thermo Scientific) with NanoESI positive ionization. Each sample was reconstituted in $\mathrm{MeOH}$ and diluted with $\mathrm{CH}_{3} \mathrm{CN} / \mathrm{H}_{2} \mathrm{O}$ /formic acid (50:50:1) for MS analysis. The sample was introduced by direct infusion (Automated Nanoelectrospray). The NanoMate (Advion BioSciences, Ithaca, NY, USA) aspirated the samples from a 384-well plate (protein Lobind) with disposable, conductive pipette tips, and infused the samples through the nanoESI Chip (which consists of 400 nozzles in a $20 \times 20$ array) towards the mass spectrometer. Spray voltage was $1.70 \mathrm{kV}$, delivery pressure $0.50 \mathrm{psi}$ and $\mathrm{m} / \mathrm{z}$ range 50-2000 Da. Data was acquired with Xcalibur software, vs.2.0SR2 (ThermoScientific). Elemental composition from experimental exact mass monoisotopic value was obtained with a dedicated algorithm integrated in Xcalibur software. Data are reported as mass-to-charge ratio $(\mathrm{m} / \mathrm{z})$ of the corresponding positively charged molecular ion. 


\section{Synthetic protocols for the preparation of the 'head' module}

Compound 1 ('head' module) was prepared via a 5-step synthesis starting from commercially available materials (Scheme S1). Azobenzene 5 was obtained by reduction of its nitro precursor 4 with sodium sulfide nonahydrate. Pyroglutamate derivative 6, prepared as previously described, (Volgraf et al, 2006) was coupled to compound $\mathbf{5}$ using HOBt/EDC activation to give the intermediate 7, and then converted via mesylation into the corresponding azide derivative $\mathbf{8}$. Hydrolysis of the pyroglutamate moiety with concomitant saponification of the ethyl ester provided the advanced intermediate $\mathbf{9}$, which was finally converted into the desired compound $\mathbf{1}$ via removal of the tertbutoxycarbonyl protecting group under acidic conditions.
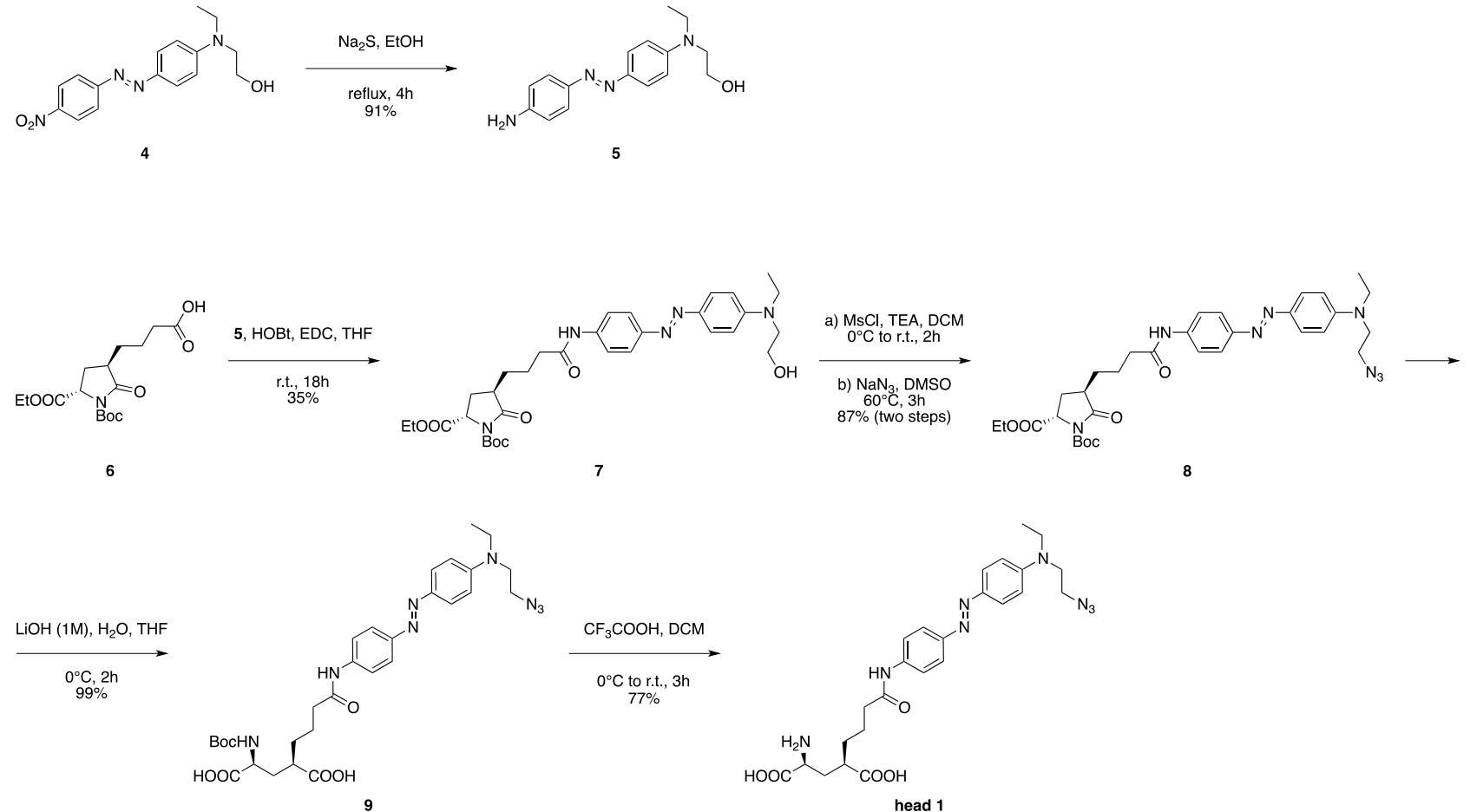

Supplementary Scheme S1. Chemical synthesis of the 'head' module (compound 1) 


\section{(E)-2-((4-((4-aminophenyl)diazenyl)phenyl)(ethyl)amino)ethanol [5]}<smiles>CCN(CCO)c1ccc(/N=N/c2ccc([N+](=O)[O-])cc2)cc1</smiles>

4

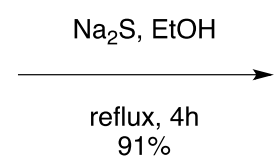

$\mathrm{H}_{2} \mathrm{~N}$<smiles>CCN(CCO)c1ccc(/N=N/c2ccc(N)cc2)cc1</smiles>

5

To a solution of (E)-2-(ethyl(4-((4-nitrophenyl)diazenyl)phenyl)amino)ethanol [4] (2.56 g, 8.14 $\mathrm{mmol})$ in ethanol $(250 \mathrm{~mL})$ was added $\mathrm{Na}_{2} \mathrm{~S} \cdot 9 \mathrm{H}_{2} \mathrm{O}(2.35 \mathrm{~g}, 9.77 \mathrm{mmol})$ and the reaction mixture was refluxed for $4 \mathrm{~h}$. The mixture was then concentrated under reduced pressure and ethyl acetate (200 $\mathrm{mL}$ ) was added to the residue. The organic layer was washed with water $(200 \mathrm{~mL})$ and brine $(200$ $\mathrm{mL}$ ), dried over $\mathrm{MgSO}_{4}$, filtered and evaporated under reduced pressure to afford compound [5] as a dark red solid which was used in the next step without further purification ( $2.10 \mathrm{~g}, 91 \%$ yield).

$R_{\mathrm{f}}=0.33$ (TLC in cyclohexane/ethyl acetate $\left.=1: 1\right)$.

m.p. $=144^{\circ} \mathrm{C}$.

${ }^{1} \mathrm{H}$ NMR (400 MHz, CD $\left.3 \mathrm{OD}\right) \delta 7.73-7.66(\mathrm{~m}, 2 \mathrm{H}), 7.64-7.58(\mathrm{~m}, 2 \mathrm{H}), 6.83-6.77(\mathrm{~m}, 2 \mathrm{H}), 6.77-$ $6.71(\mathrm{~m}, 2 \mathrm{H}), 3.74(\mathrm{t}, \mathrm{J}=6.4 \mathrm{~Hz}, 2 \mathrm{H}), 3.58-3.48(\mathrm{~m}, 4 \mathrm{H}), 1.20(\mathrm{t}, \mathrm{J}=7.1 \mathrm{~Hz}, 3 \mathrm{H})$.

${ }^{13} \mathrm{CNMR}\left(101 \mathrm{MHz}, \mathrm{CD}_{3} \mathrm{OD}\right) \delta 151.73,150.98,146.24,144.62,125.18,124.95,115.55,112.46,60.35$, $53.43,46.65,12.45$.

HRMS $(m / z)$ calculated for $\mathrm{C}_{16} \mathrm{H}_{21} \mathrm{~N}_{4} \mathrm{O}^{+}[\mathrm{M}+\mathrm{H}]^{+}: 285.17099$, found: $285.17032\left(\Delta_{\mathrm{ppm}}=-2.34\right)$. 
(2S,4R)-1-tert-butyl 2-ethyl 4-(4-((4-((E)-(4-(ethyl(2-hydroxyethyl)amino)phenyl)diazenyl)phenyl) amino)-4-oxobutyl)-5-oxopyrrolidine-1,2-dicarboxylate [7]

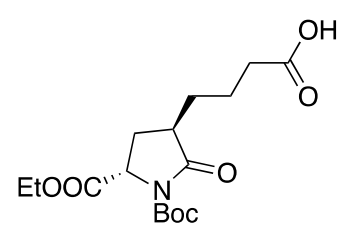

6
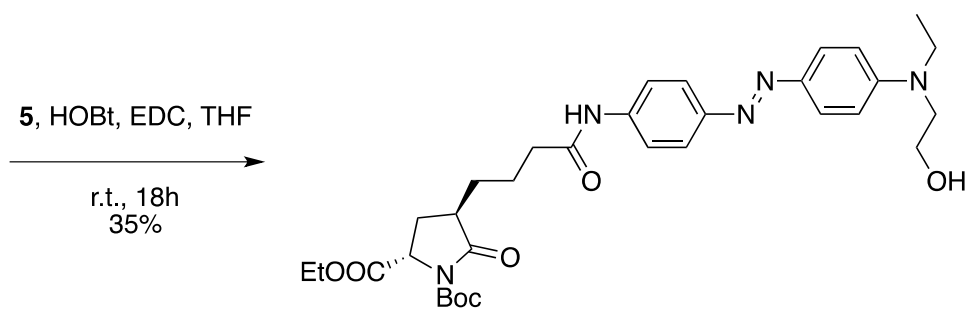

7

A suspension of 4-((3R,5S)-1-(tert-butoxycarbonyl)-5-(ethoxycarbonyl)-2-oxopyrrolidin-3yl)butanoic acid [6] (250 mg, $0.73 \mathrm{mmol}$ ), 1-hydroxybenzotriazole hydrate ( $\mathrm{HOBt} \cdot \mathrm{xH}_{2} \mathrm{O}, 223 \mathrm{mg}, 1.46$ $\mathrm{mmol}$ ) and $\mathrm{N}$-(3-dimethylaminopropyl)- $\mathrm{N}^{\prime}$-ethylcarbodiimide hydrochloride (EDC.HCl, $279 \mathrm{mg}, 1.46$ $\mathrm{mmol})$ in anhydrous tetrahydrofuran $(20 \mathrm{~mL})$ was stirred at room temperature for $30 \mathrm{~min}$. (E)-2-((4((4-aminophenyl)diazenyl)phenyl)(ethyl)amino)ethanol [5] (311 mg, $1.09 \mathrm{mmol}$ ) was then added and the resulting mixture was stirred at room temperature for $18 \mathrm{~h}$. The solvent was then evaporated and the residue was purified by direct flash chromatography (100\% diethyl ether until complete elution of unreacted compound [5], then dichloromethane/methanol $=100: 0$ to 95:5 gradient) to afford compound [7] as a dark red oil (156 mg, 35\% yield).

$R_{\mathrm{f}}=0.34$ (TLC in cyclohexane/ethyl acetate $=2: 8$ ).

$[\alpha]_{D}=-3.23(c=0.155$, methanol).

${ }^{1} \mathrm{H} \mathrm{NMR}\left(400 \mathrm{MHz}, \mathrm{CDCl}_{3}\right) \delta 8.15(\mathrm{~s}, 1 \mathrm{H}), 7.78(\mathrm{dd}, \mathrm{J}=8.9,6.7 \mathrm{~Hz}, 4 \mathrm{H}), 7.64(\mathrm{~d}, \mathrm{~J}=8.8 \mathrm{~Hz}, 2 \mathrm{H}), 6.75$ $(d, J=9.2 \mathrm{~Hz}, 2 \mathrm{H}), 4.55(\mathrm{dd}, \mathrm{J}=9.6,1.5 \mathrm{~Hz}, 1 \mathrm{H}), 4.22(\mathrm{q}, \mathrm{J}=7.1 \mathrm{~Hz}, 2 \mathrm{H}), 3.83(\mathrm{t}, \mathrm{J}=6.0 \mathrm{~Hz}, 2 \mathrm{H}), 3.54$ $(\mathrm{t}, \mathrm{J}=6.0 \mathrm{~Hz}, 2 \mathrm{H}), 3.48(\mathrm{q}, \mathrm{J}=7.0 \mathrm{~Hz}, 2 \mathrm{H}), 2.64(\mathrm{dtd}, \mathrm{J}=11.6,8.5,4.7 \mathrm{~Hz}, 1 \mathrm{H}), 2.51(\mathrm{~s}, 1 \mathrm{H}), 2.39$ (td, J $=7.2,4.2 \mathrm{~Hz}, 2 \mathrm{H}$ ), 2.24 (ddd, J=13.2, 8.7, $1.5 \mathrm{~Hz}, 1 \mathrm{H}$ ), 2.00 (ddd, J = 13.3, 11.7, $9.7 \mathrm{~Hz}, 1 \mathrm{H}$ ), $1.94-$ $1.82(\mathrm{~m}, 1 \mathrm{H}), 1.76(\mathrm{ddd}, \mathrm{J}=13.7,10.7,6.9 \mathrm{~Hz}, 2 \mathrm{H}), 1.47(\mathrm{~s}, 9 \mathrm{H}), 1.51-1.37(\mathrm{~m}, 1 \mathrm{H}), 1.28(\mathrm{t}, \mathrm{J}=7.1$ $\mathrm{Hz}, 3 \mathrm{H}), 1.19(\mathrm{t}, \mathrm{J}=7.0 \mathrm{~Hz}, 3 \mathrm{H})$.

${ }^{13} \mathrm{CNMR}\left(101 \mathrm{MHz}, \mathrm{CDCl}_{3}\right) \delta 175.75,171.35,171.26,150.45,149.51,149.43,143.67,139.45,125.10$, $123.12,120.08,111.67,83.87,61.91,60.21,57.38,52.51,45.89,41.64,37.22,29.76,28.45,28.00$, $22.81,14.32,12.19$.

HRMS $(m / z)$ calculated for $\mathrm{C}_{32} \mathrm{H}_{44} \mathrm{~N}_{5} \mathrm{O}_{7}+[\mathrm{M}+\mathrm{H}]^{+}: 610.32353$, found: $610.32276\left(\Delta_{\mathrm{ppm}}=-1.25\right)$. 
(2S,4R)-1-tert-butyl 2-ethyl 4-(4-((4-((E)-(4-((2-azidoethyl)(ethyl)amino)phenyl)diazenyl)phenyl) amino)-4-oxobutyl)-5-oxopyrrolidine-1,2-dicarboxylate [8]<smiles>CCOC(=O)[C@@H]1CC(CCCC(=O)Nc2ccc(N=Nc3ccc(N(CC)CCO)cc3)cc2)C(=O)[C@@H]1OC(C)(C)C</smiles>

7

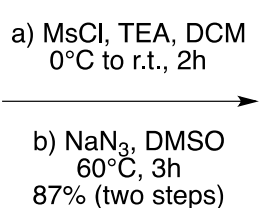

$87 \%$ (two steps)

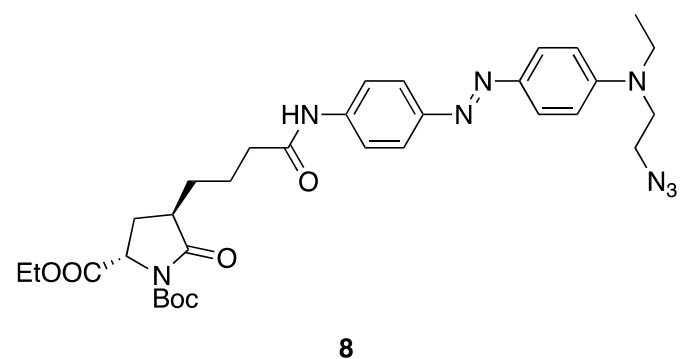

2-ethyl

4-(4-((4-)((E)-(4-(ethy) (2dicarboxylate [7] $(136 \mathrm{mg}, 0.22 \mathrm{mmol})$ in anhydrous dichloromethane $(15 \mathrm{~mL})$ at $0{ }^{\circ} \mathrm{C}$ was added triethylamine ( $187 \mu \mathrm{L}, 1.34 \mathrm{mmol}$ ) followed by a slow addition of methanesulfonyl chloride ( $86 \mu \mathrm{L}$, $1.12 \mathrm{mmol})$. After $2 \mathrm{~h}$ of stirring at room temperature, the filtrate was concentrated to an oil and dissolved in dimethylsulfoxide $(2 \mathrm{~mL}$ ). Sodium azide (73 mg, $1.12 \mathrm{mmol}$ ) was then added and the mixture was stirred at $60^{\circ} \mathrm{C}$ for $3 \mathrm{~h}$ in a sealed vessel. The reaction mixture was then allowed to cool to room temperature, diluted with brine $(200 \mathrm{~mL})$ and extracted with diethyl ether $(3 \times 200 \mathrm{~mL})$. The combined organic layers were dried over $\mathrm{MgSO}_{4}$, filtered and evaporated to dryness. Purification by direct flash chromatography ( $n$-hexane/ethyl acetate $=80: 20$ to $20: 80$ gradient) afforded compound [8] as an orange oil (123 mg, 87\% yield).

$R_{\mathrm{f}}=0.58($ TLC in cyclohexane/ethyl acetate $=2: 8)$.

$[\alpha]_{D}=-2.63(c=0.165$, methanol $)$.

${ }^{1} \mathrm{H}$ NMR $\left(400 \mathrm{MHz}, \mathrm{CDCl}_{3}\right) \delta 7.94(\mathrm{~s}, 1 \mathrm{H}), 7.83(\mathrm{dd}, \mathrm{J}=9.9,9.0 \mathrm{~Hz}, 4 \mathrm{H}), 7.68(\mathrm{~d}, \mathrm{~J}=8.8 \mathrm{~Hz}, 2 \mathrm{H}), 6.75$ $(d, J=9.2 \mathrm{~Hz}, 2 \mathrm{H}), 4.57(\mathrm{dd}, \mathrm{J}=9.6,1.4 \mathrm{~Hz}, 1 \mathrm{H}), 4.23(\mathrm{q}, \mathrm{J}=7.1 \mathrm{~Hz}, 2 \mathrm{H}), 3.58(\mathrm{t}, \mathrm{J}=6.0 \mathrm{~Hz}, 2 \mathrm{H}), 3.55$ $-3.47(\mathrm{~m}, 4 \mathrm{H}), 2.67(\mathrm{dtd}, \mathrm{J}=11.7,8.4,4.8 \mathrm{~Hz}, 1 \mathrm{H}), 2.43(\mathrm{td}, \mathrm{J}=7.2,5.0 \mathrm{~Hz}, 2 \mathrm{H}), 2.27$ (ddd, J = 13.3, 8.7, $1.5 \mathrm{~Hz}, 1 \mathrm{H}$ ), 2.02 (ddd, J = 13.3, 11.7, 9.6 Hz, 1H), 1.93 (dtd, J = 17.7, 7.4, $4.8 \mathrm{~Hz}, 1 \mathrm{H}$ ), $1.87-1.74$ $(m, 2 H), 1.58-1.44(m, 1 H), 1.49(s, 9 H), 1.29(t, J=7.1 \mathrm{~Hz}, 3 \mathrm{H}), 1.23(t, J=7.1 \mathrm{~Hz}, 3 \mathrm{H})$.

${ }^{13} \mathrm{C} \mathrm{NMR}\left(101 \mathrm{MHz} \mathrm{CDCl}_{3}\right) \delta$ 175.57, 171.36, 171.03, 149.54, 149.49, 149.47, 144.06, 139.54, 125.14, $123.26,119.98,111.63,83.81,61.90,57.35,49.70,49.10,45.92,41.67,37.31,29.78,28.53,28.03$, $22.84,14.34,12.42$.

HRMS $(m / z)$ calculated for $\mathrm{C}_{32} \mathrm{H}_{43} \mathrm{~N}_{8} \mathrm{O}_{6}{ }^{+}[\mathrm{M}+\mathrm{H}]^{+}: 635.33001$, found: $635.32940\left(\Delta_{\mathrm{ppm}}=-0.96\right)$. 


\section{(2R,4S)-2-(4-((4-((E)-(4-((2-azidoethyl)(ethyl)amino)phenyl)diazenyl)phenyl)amino)-4-oxobutyl)-} 4-((tert-butoxycarbonyl)amino)pentanedioic acid [9]

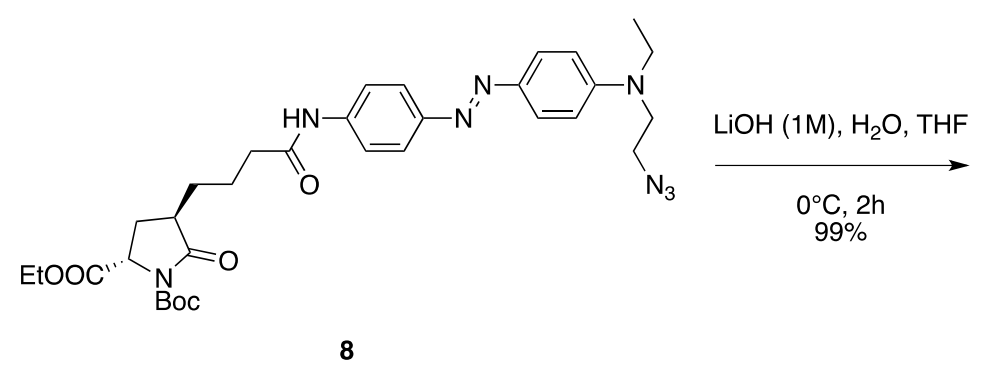

To a solution of

$(2 S, 4 R)$-1-tert-butyl

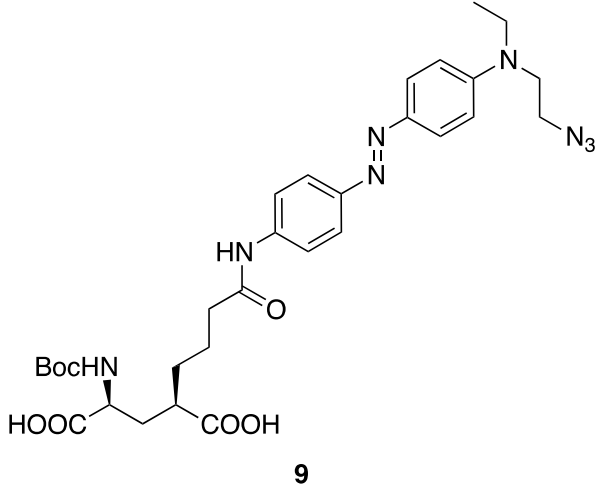

2-ethyl
4-(4- $((4-)((E)-(4-)((2-$

azidoethyl)(ethyl)amino)phenyl)diazenyl)phenyl)amino)-4-oxobutyl)-5-oxopyrrolidine-1,2-

dicarboxylate [8] $(133 \mathrm{mg}, 0.21 \mathrm{mmol})$ in tetrahydrofuran $(6.3 \mathrm{~mL})$ at $0{ }^{\circ} \mathrm{C}$ was added a $1.0 \mathrm{M}$ aqueous solution of lithium hydroxide $(6.3 \mathrm{~mL})$ and the resulting mixture was stirred at $0{ }^{\circ} \mathrm{C}$ for $2 \mathrm{~h}$. The reaction was then acidified to $\mathrm{pH} 2$ with $1.0 \mathrm{M} \mathrm{H}_{2} \mathrm{SO}_{4}$ and extracted with ethyl acetate $(5 \times 30$ $\mathrm{mL}$ ). The combined organic layers were dried over $\mathrm{MgSO}_{4}$, filtered and evaporated to dryness to afford compound [9] as a dark red oil which was used in the next step without further purification (130 mg, 99\% yield).

$R_{\mathrm{f}}=0.55$ (TLC in dichloromethane/methanol $=8: 2$ ).

$[\alpha]_{D}=+14.57(\mathrm{c}=0.270$, methanol).

${ }^{1} \mathrm{H}$ NMR (400 MHz, CD 30 O) $\delta 7.81(d, J=9.2 \mathrm{~Hz}, 2 \mathrm{H}), 7.78(\mathrm{~d}, \mathrm{~J}=8.9 \mathrm{~Hz}, 2 \mathrm{H}), 7.70(\mathrm{~d}, \mathrm{~J}=9.0 \mathrm{~Hz}, 2 \mathrm{H})$, $6.87(\mathrm{~d}, \mathrm{~J}=9.3 \mathrm{~Hz}, 2 \mathrm{H}), 4.17-4.06(\mathrm{~m}, 1 \mathrm{H}), 3.64(\mathrm{t}, \mathrm{J}=6.1 \mathrm{~Hz}, 2 \mathrm{H}), 3.61-3.50(\mathrm{~m}, 4 \mathrm{H}), 2.65-2.50$ $(\mathrm{m}, 1 \mathrm{H}), 2.43(\mathrm{t}, \mathrm{J}=7.1 \mathrm{~Hz}, 2 \mathrm{H}), 2.30-2.12(\mathrm{~m}, 1 \mathrm{H}), 2.10-1.89(\mathrm{~m}, 1 \mathrm{H}), 1.88-1.67(\mathrm{~m}, 4 \mathrm{H}), 1.67-$ $1.55(\mathrm{~m}, 1 \mathrm{H}), 1.44(\mathrm{~s}, 9 \mathrm{H}), 1.24(\mathrm{t}, \mathrm{J}=7.0 \mathrm{~Hz}, 3 \mathrm{H})$.

${ }^{13} \mathrm{C}$ NMR (101 MHz, CD $\left.{ }_{3} \mathrm{OD}\right) \delta 178.71,176.05,174.15,151.36,150.63,144.94,141.34,125.98$, $123.80,121.22,112.74,80.49,53.56,50.47,50.27,46.49,43.15,37.74,34.90,33.44,30.13,28.73$, $24.46,12.46$.

HRMS $(m / z)$ calculated for $\mathrm{C}_{30} \mathrm{H}_{41} \mathrm{~N}_{8} \mathrm{O}_{7}{ }^{+}[\mathrm{M}+\mathrm{H}]^{+}:$625.30927, found: $625.30847\left(\Delta_{\mathrm{ppm}}=-1.28\right)$. 


\section{(2S,4R)-2-amino-4-(4-((4-((E)-(4-((2-azidoethyl)(ethyl)amino)phenyl)diazenyl)phenyl)amino)-4-} oxobutyl)pentanedioic acid [1]
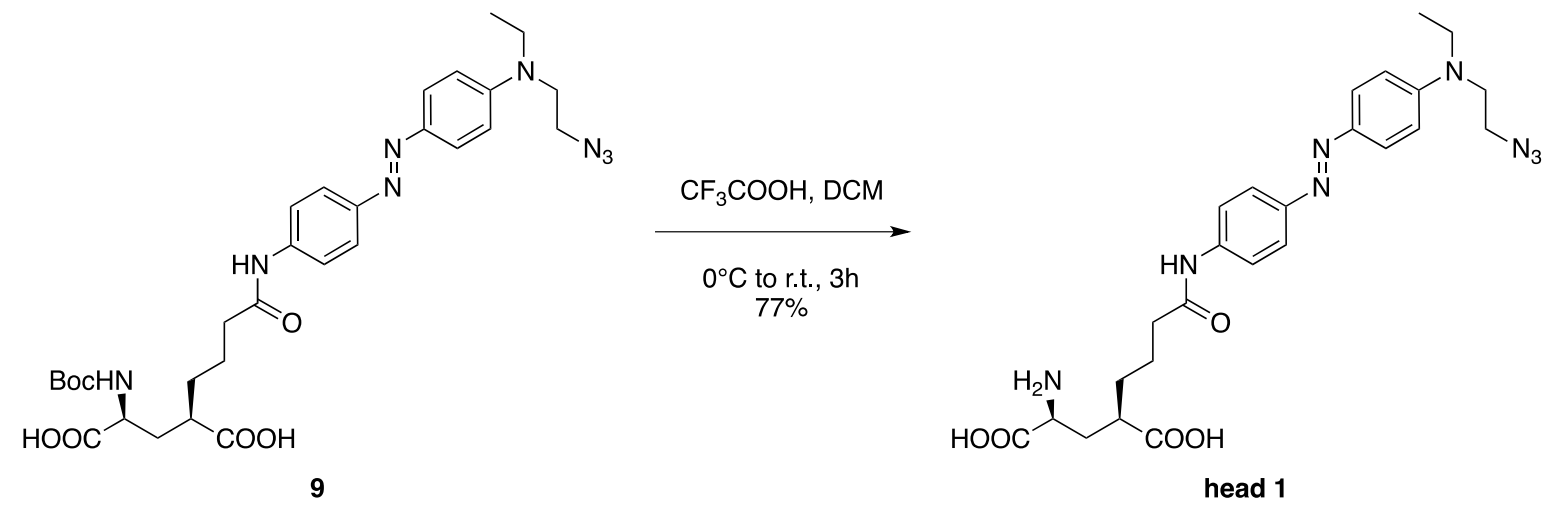

Trifluoroacetic acid (313 $\mu \mathrm{L}, 4.09 \mathrm{mmol})$ was added dropwise to a solution of $(2 R, 4 S)-2-(4-((4-)((E)-$ (4-((2-azidoethyl)(ethyl)amino)phenyl)diazenyl)phenyl)amino)-4-oxobutyl)-4-((tert-

butoxycarbonyl)amino)pentanedioic acid [9] $(128 \mathrm{mg}, 0.20 \mathrm{mmol})$ in anhydrous DCM (15 $\mathrm{mL})$ at 0 ${ }^{\circ} \mathrm{C}$, and the resulting solution was stirred at room temperature for $3 \mathrm{~h}$. The solvent was then removed under reduced pressure and the residue was purified by reversed-phase flash chromatography (water/acetonitrile $=100: 0$ to 0:100 gradient) to afford compound [1] as an orange solid ( $83 \mathrm{mg}, 77 \%$ yield; purity $\geq 99 \%$ as determined by HPLC-PDA analysis).

$R_{\mathrm{f}}=0.10($ TLC in dichloromethane/methanol $=8: 2)$.

m.p. $=150^{\circ} \mathrm{C}$ (dec.).

$[\alpha]_{D}=+11.70(c=0.265$, methanol).

${ }^{1} \mathrm{H}$ NMR $\left(500 \mathrm{MHz}, \mathrm{CD}_{3} \mathrm{OD}\right) \delta 7.84-7.78(\mathrm{~m}, 2 \mathrm{H}), 7.81-7.74(\mathrm{~m}, 2 \mathrm{H}), 7.74-7.68(\mathrm{~m}, 2 \mathrm{H}), 6.91-$ $6.83(\mathrm{~m}, 2 \mathrm{H}), 3.69-3.61(\mathrm{~m}, 3 \mathrm{H}), 3.61-3.51(\mathrm{~m}, 4 \mathrm{H}), 2.68-2.59(\mathrm{~m}, 1 \mathrm{H}), 2.48-2.41(\mathrm{~m}, 2 \mathrm{H}), 2.28$ (ddd, J = 14.7, 9.0, 4.7 Hz, 1H), $1.93(d d d, J=14.7,8.5,4.7 \mathrm{~Hz}, 1 \mathrm{H}), 1.86-1.72(\mathrm{~m}, 4 \mathrm{H}), 1.72-1.61$ $(\mathrm{m}, 2 \mathrm{H}), 1.24(\mathrm{t}, \mathrm{J}=7.0 \mathrm{~Hz}, 3 \mathrm{H})$.

${ }^{13} \mathrm{C}$ NMR $\left(126 \mathrm{MHz}, \mathrm{CD}_{3} \mathrm{OD}\right) \delta 179.72,174.28,173.95,151.35,150.61,144.94,141.39,125.97$, $123.79,121.21,112.74,54.39,50.48,50.28,46.50,43.51,37.74,33.96,32.71,24.40,12.46$.

UV-Vis (PBS): $\lambda_{\max }(\mathrm{abs})=460 \mathrm{~nm}, \varepsilon=2.927 \times 10^{4} \mathrm{M}^{-1} \cdot \mathrm{cm}^{-1}$.

$R_{\mathrm{t}}$ (HPLC-PDA, XSelect CSH C18 Column) $=2.25 \mathrm{~min}$ (trans isomer).

HRMS $(m / z)$ calculated for $\mathrm{C}_{25} \mathrm{H}_{33} \mathrm{~N}_{8} \mathrm{O}_{5}{ }^{+}[\mathrm{M}+\mathrm{H}]^{+}: 525.25684$, found: $525.25883\left(\Delta_{\mathrm{ppm}}=+3.78\right)$. 


\section{Supplementary Figures}
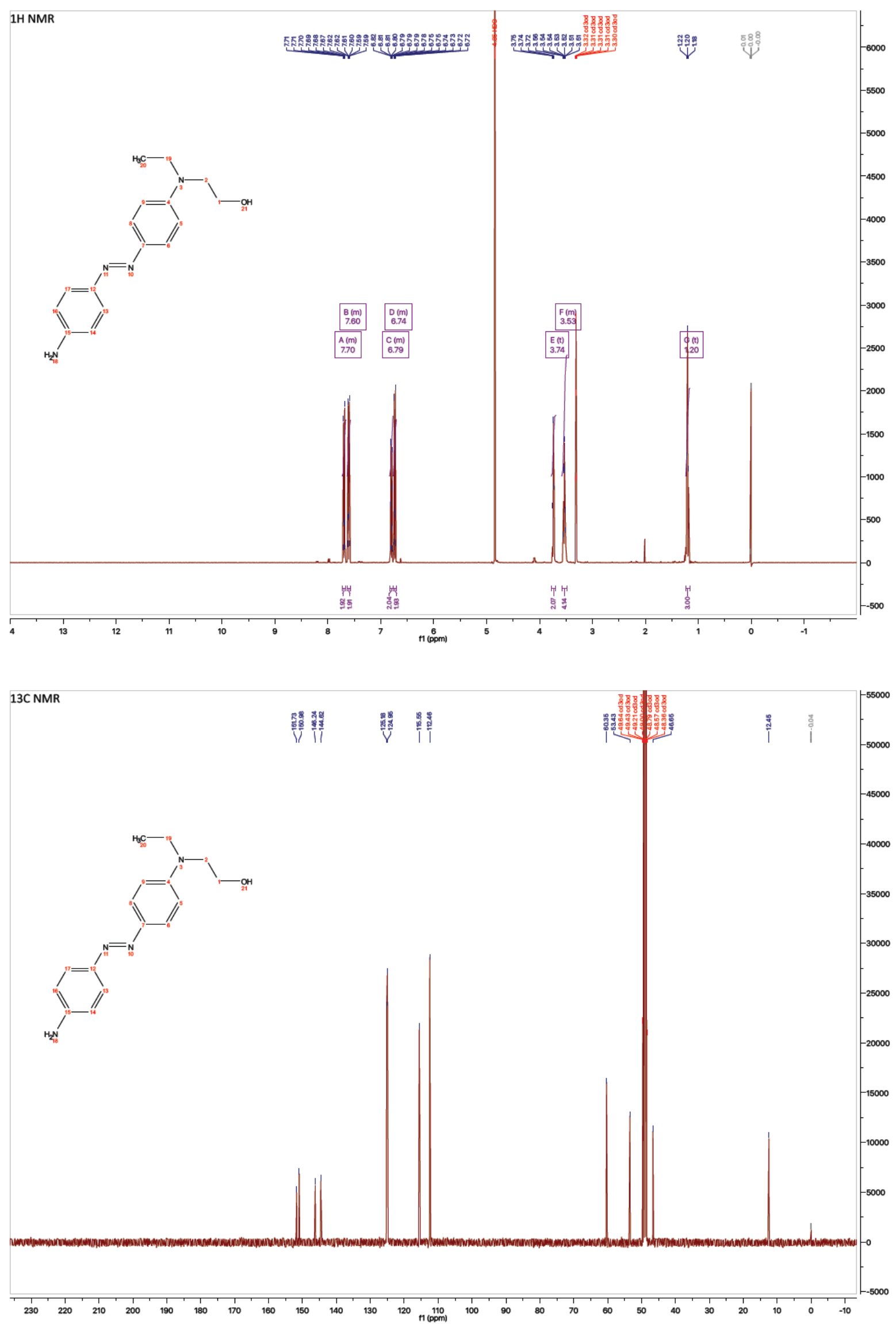

Supplementary Figure S1. NMR spectra of compound 5. 

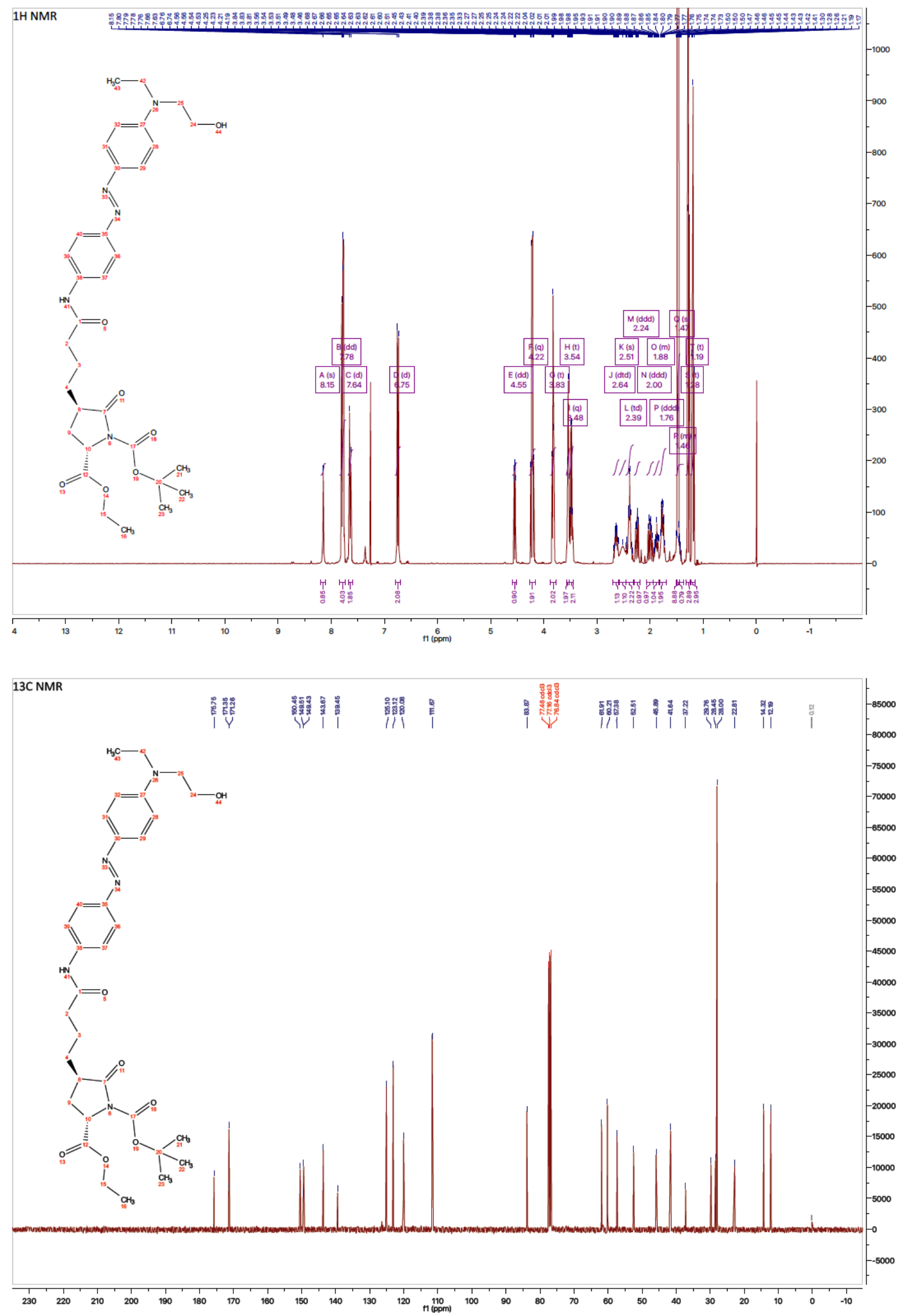

Supplementary Figure S2. NMR spectra of compound 7. 

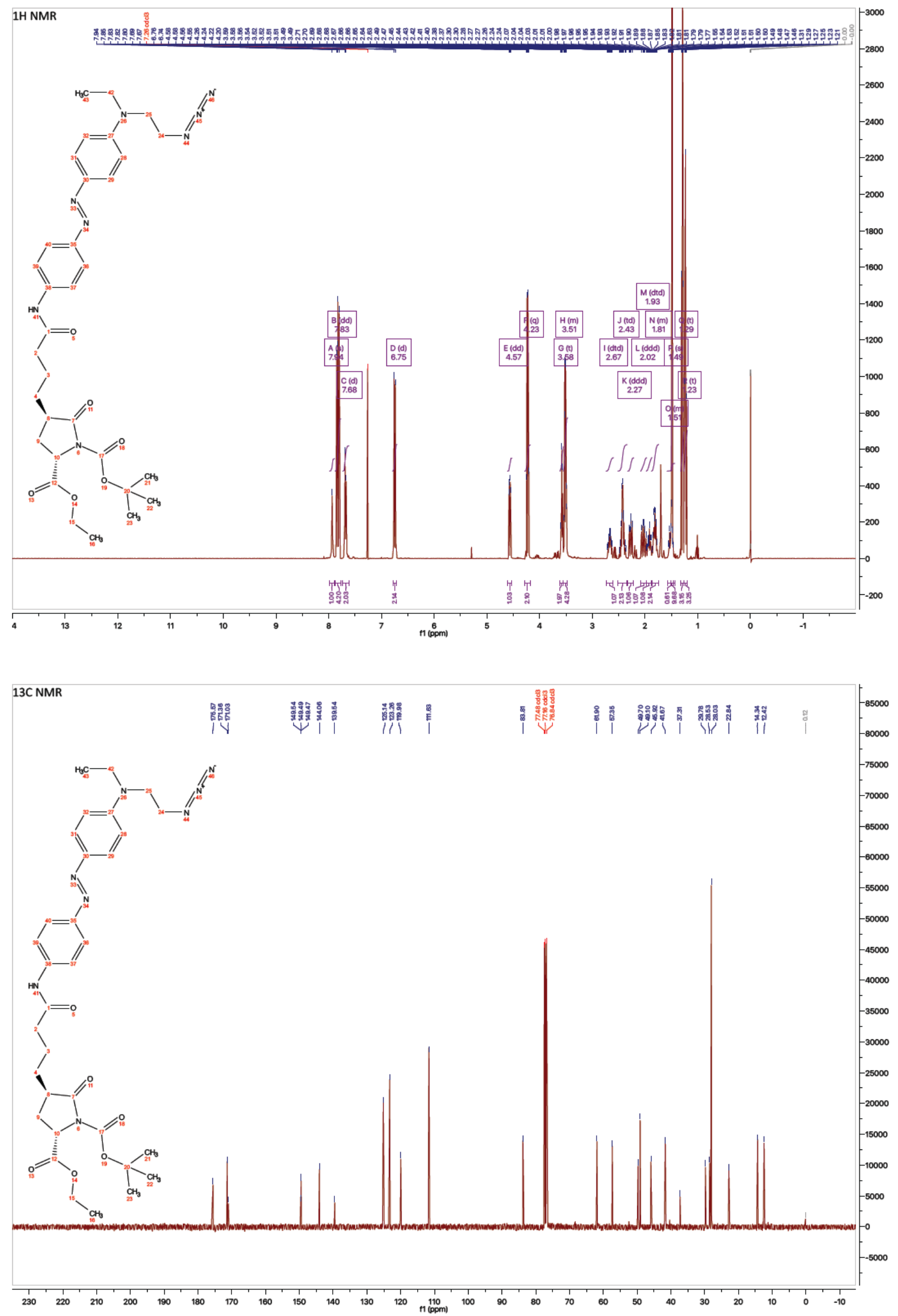

Supplementary Figure S3. NMR spectra of compound 8. 

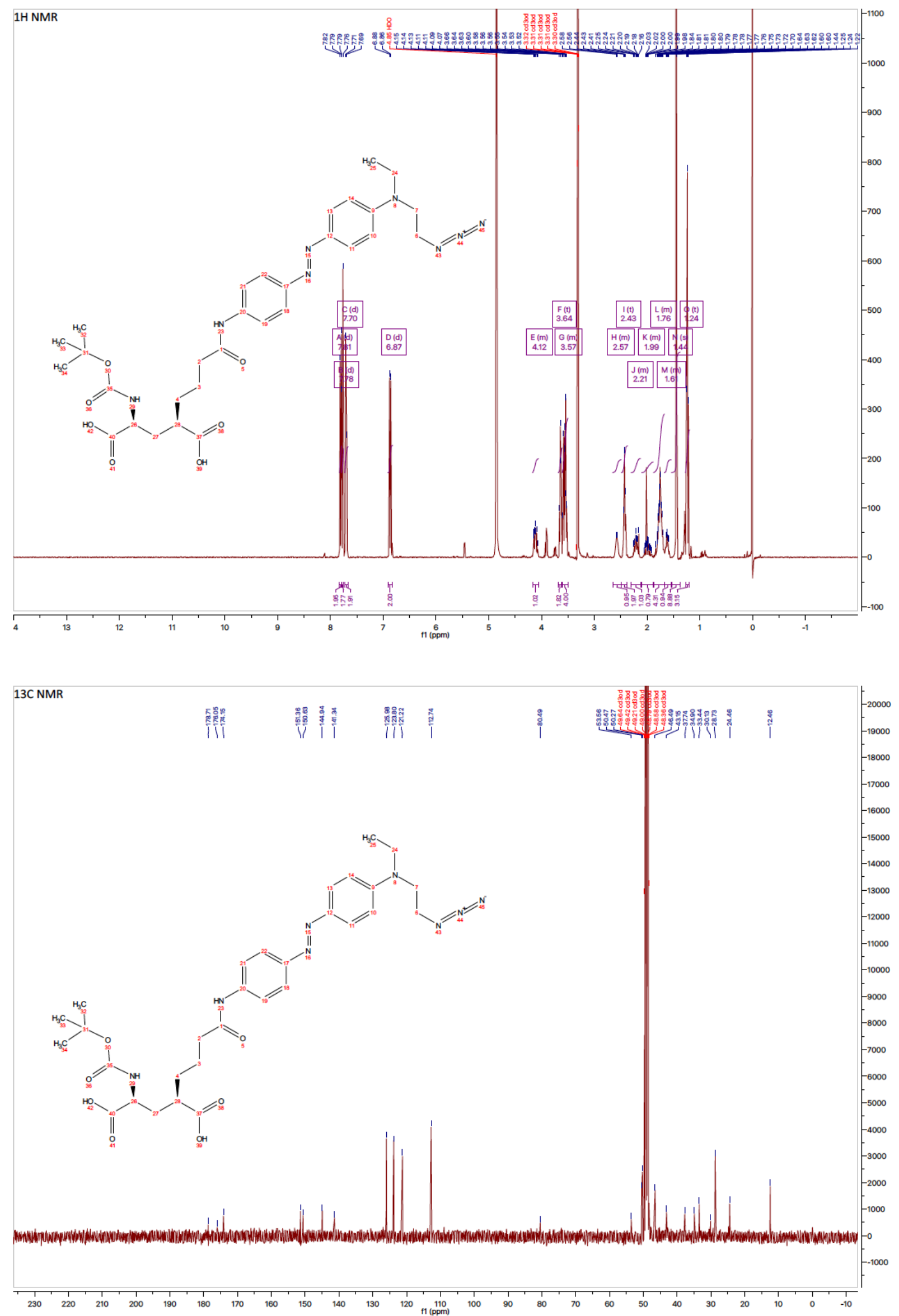

Supplementary Figure S4. NMR spectra of compound 9. 

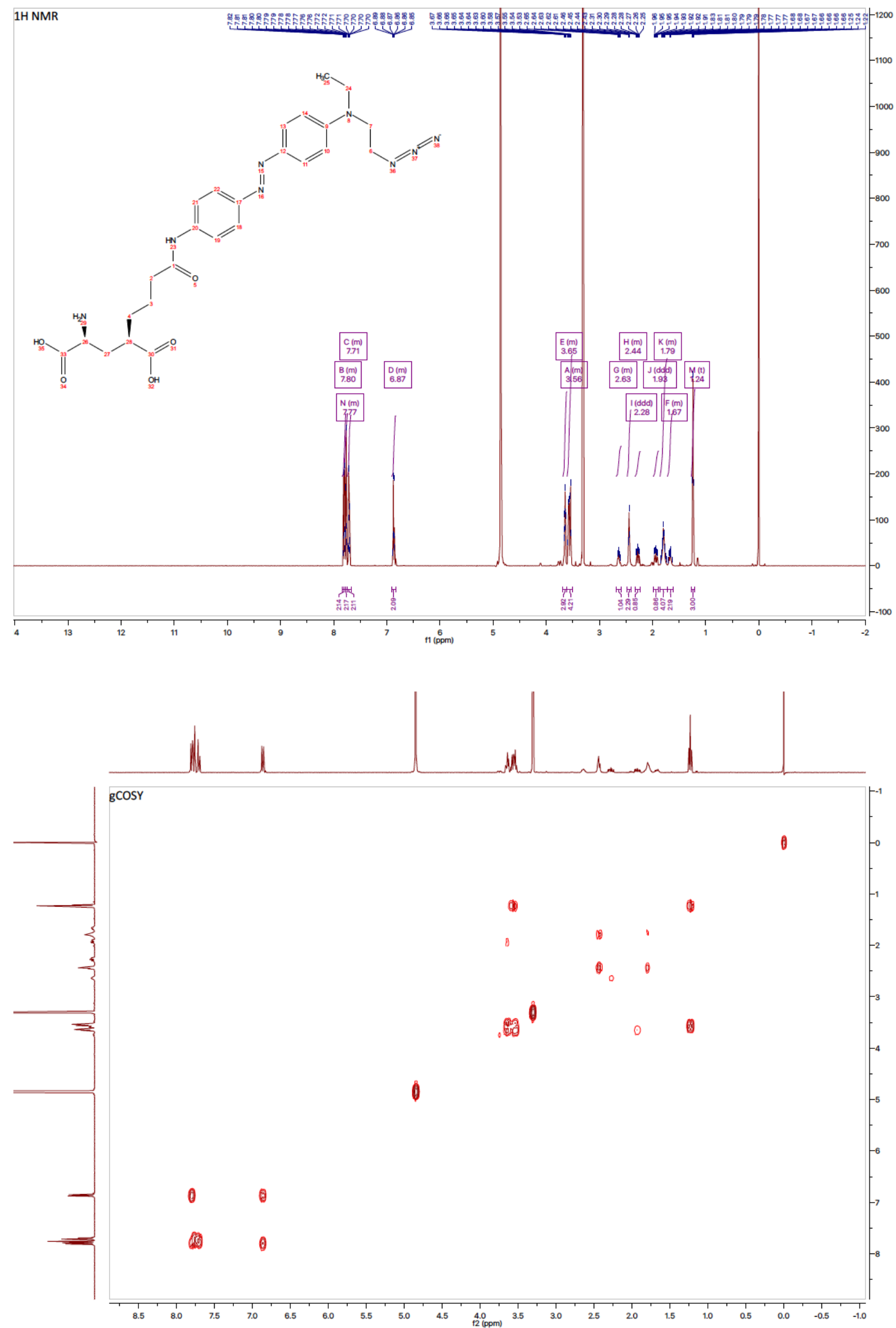

Supplementary Figure S5. NMR spectra of compound 1 (continued to the next page). 

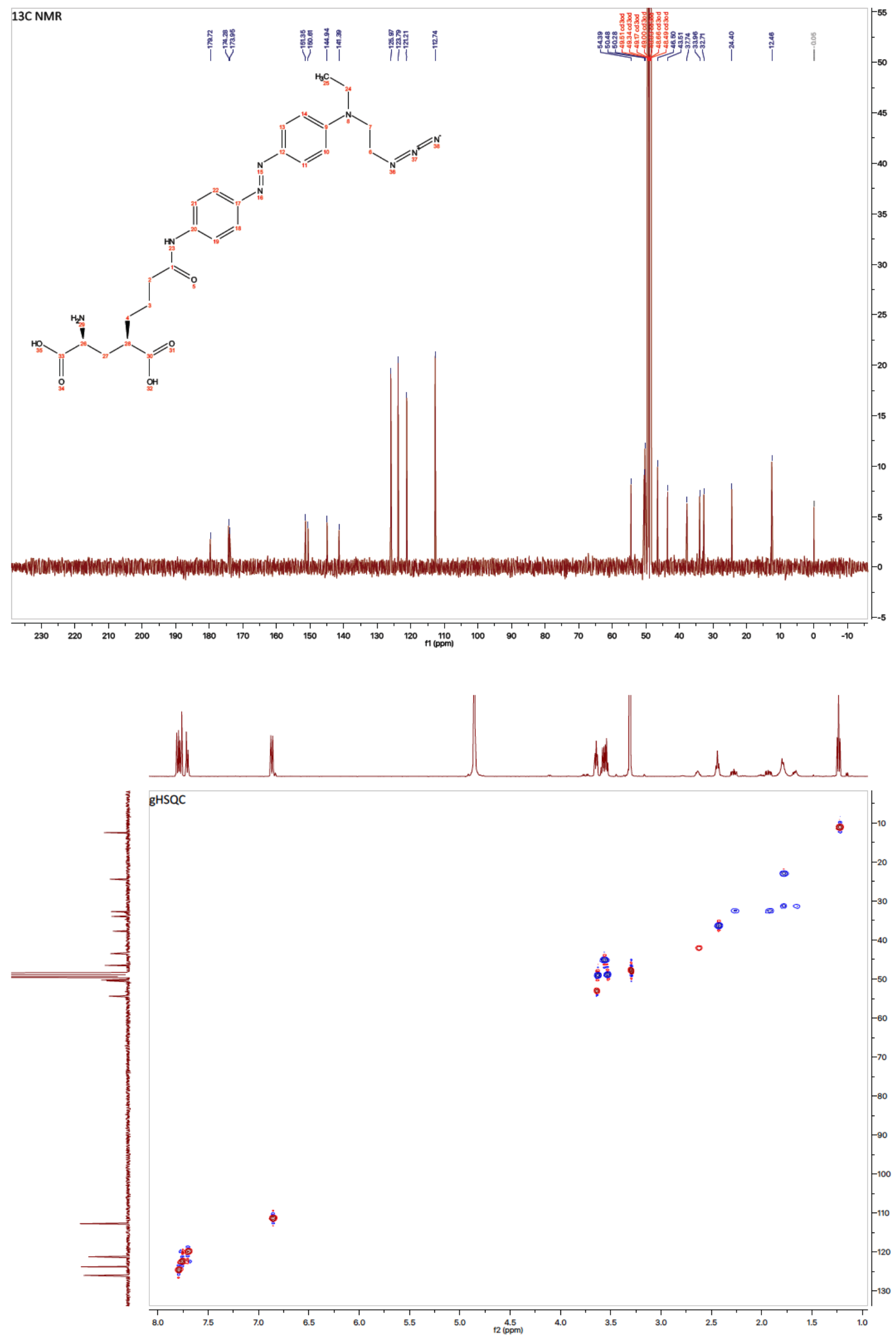

Supplementary Figure S5. NMR spectra of compound $\mathbf{1}$ (continued from the previous page). 
bioRxiv preprint doi: https://doi.org/10.1101/2021.05.25.445123; this version posted May 25, 2021. The copyright holder for this preprint (which was not certified by peer review) is the author/funder. All rights reserved. No reuse allowed without permission.

XSelect C18 4.6x50mm 3.5 $\mu \mathrm{m}$
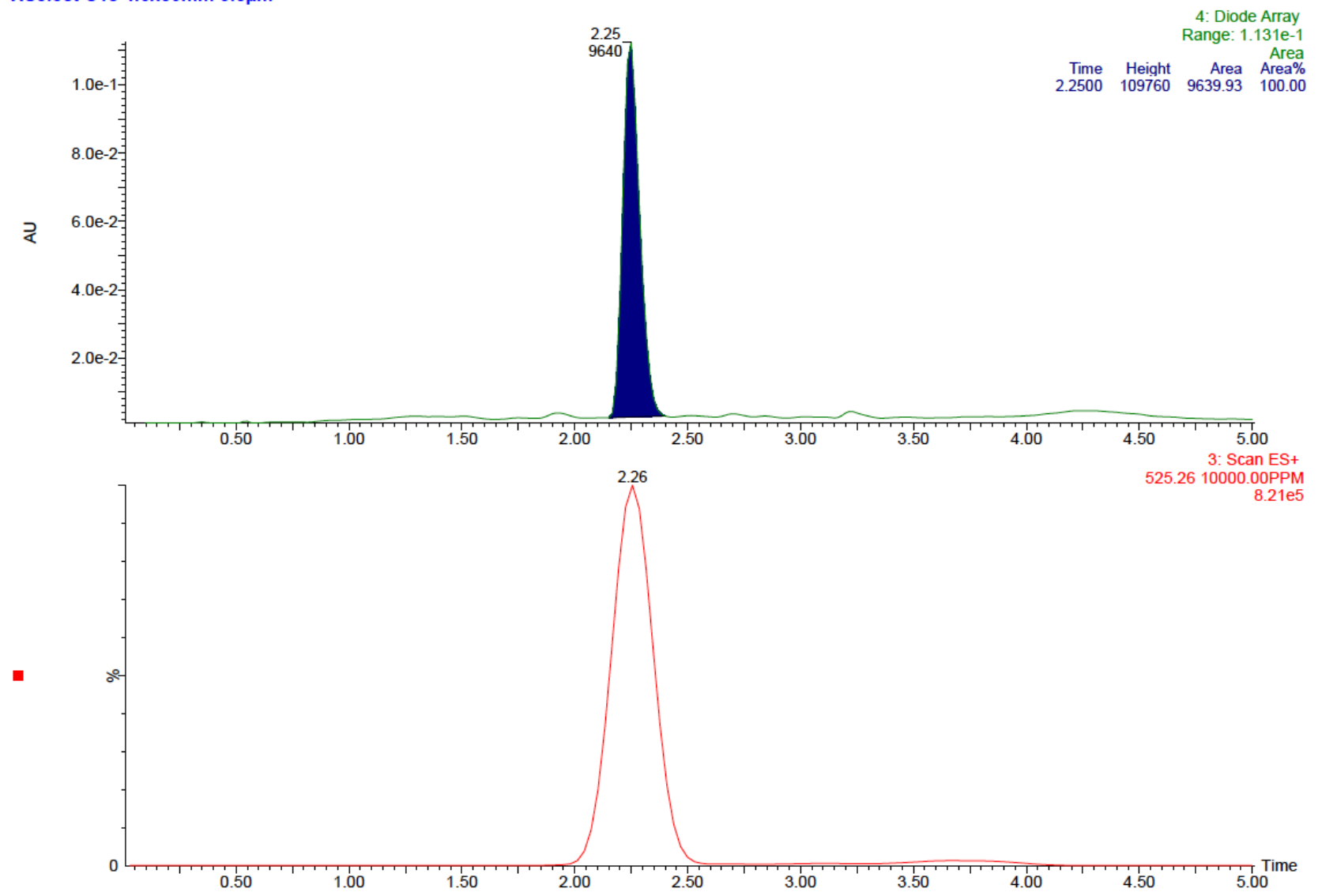

Supplementary Figure S6. HPLC chromatogram of compound 1.

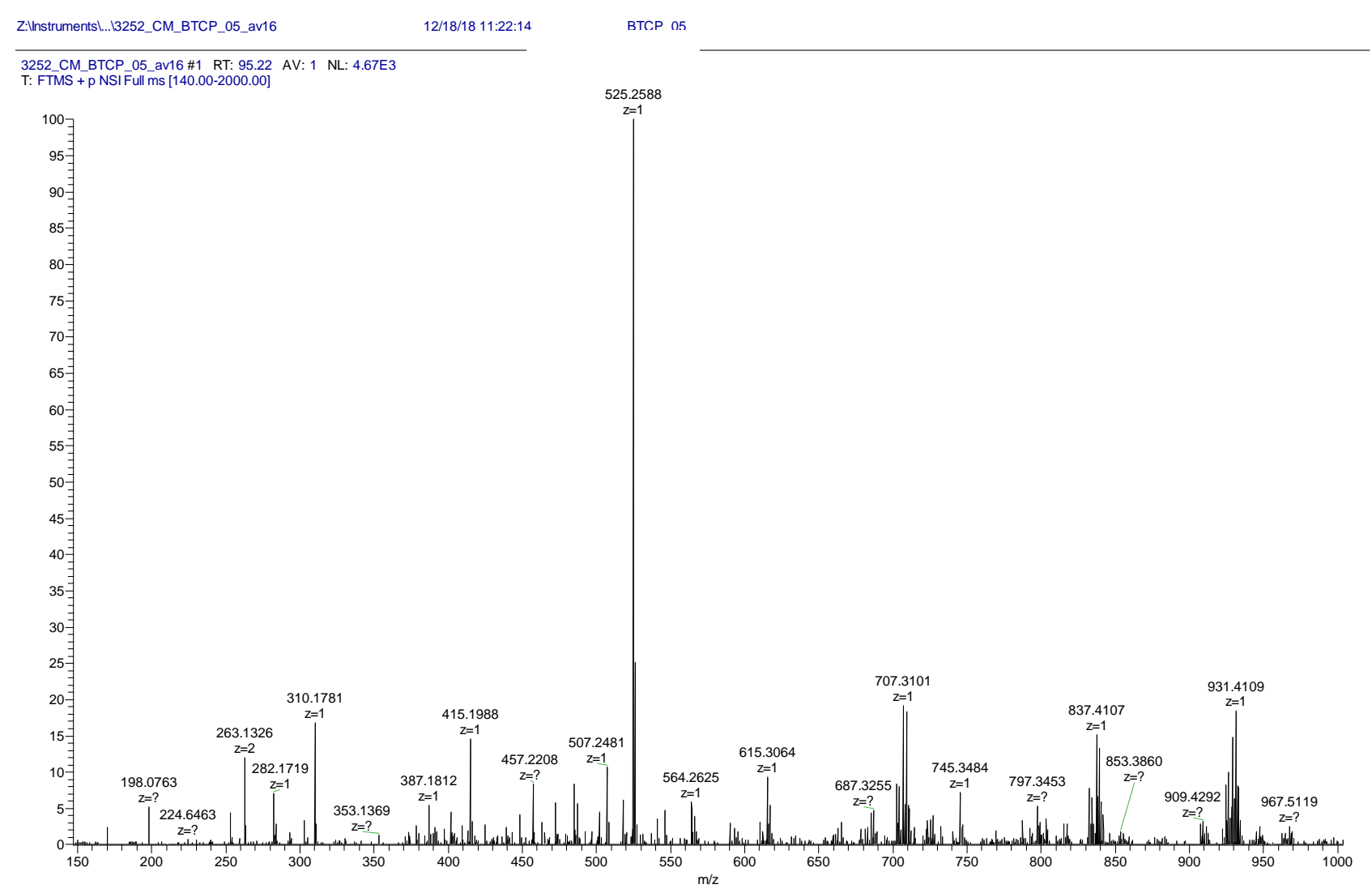

Supplementary Figure S7. High-resolution mass spectrum of compound 1. 


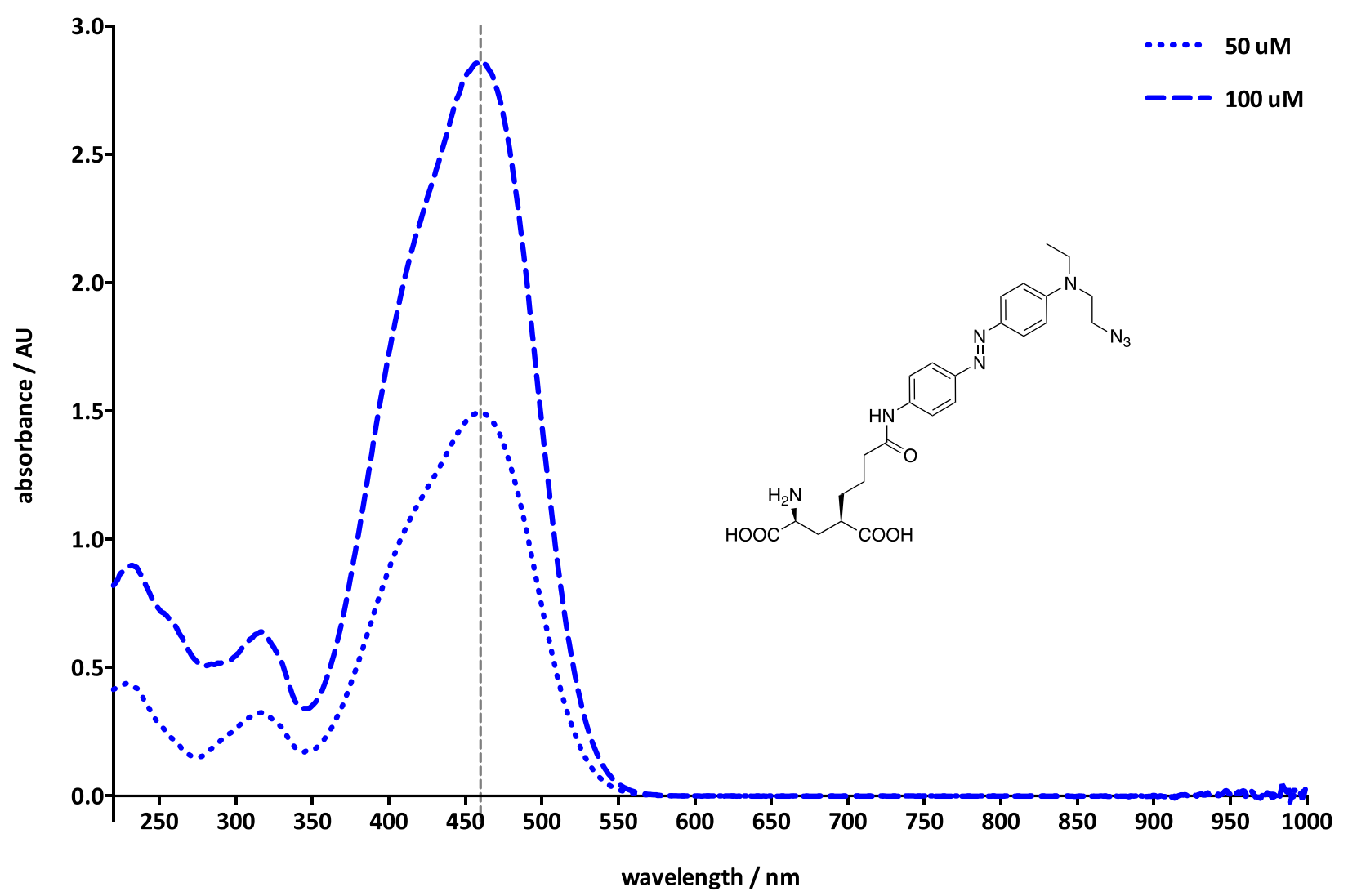

Supplementary Figure S8. UV-Vis absorption spectrum of compound $\mathbf{1}$ (trans isomer) in PBS buffer at pH 7.4. 


\section{Synthetic protocol for the preparation of TCP fast}

Head (1) and tail (2, commercially available) were combined to form the final $\mathrm{TCP}_{\text {fast }}(\mathbf{3})$ compound using a "click" version of the Huisgen azide-alkyne 1,3-dipolar cycloaddition.(Himo et al, 2005) Since such NHS-ester derivatives are very short-lived, we characterized the products of the click reaction crude of $\mathrm{TCP}_{\text {fast }}$ after subsequent reaction with pure L-lysine as a mock protein residue. Detailed analysis by LC-MS confirmed the presence of the intended $\mathrm{TCP}_{\text {fast }}-$ lysine adduct with an intact glutamate moiety and of some of the expected byproducts.

General procedure. To a $1.5 \mathrm{ml}$ glass vial containing azide 1 ('head', $1.00 \mathrm{mg}, 1 \mathrm{eq}$ ) and copper(I) oxide $(0.82 \mathrm{mg}, 3 \mathrm{eq})$ in tetrahydrofuran $(47 \mu \mathrm{L})$ and equipped with a magnetic stir bar was added a solution of ascorbic acid (1.34 mg, $4 \mathrm{eq})$ in water $(94 \mu \mathrm{L})$ and the resulting mixture was vortexed for $1 \mathrm{~min}$. Then, a solution of alkyne 2 ('tail', $0.47 \mathrm{mg}, 1.1 \mathrm{eq}$ ) in tetrahydrofuran ( $47 \mu \mathrm{L}$ ) was added and the resulting mixture was stirred at room temperature for $45 \mathrm{~min}$. The so-obtained final mixture was taken up in dimethylsulfoxide $(193 \mu \mathrm{L})$, vortexed, centrifuged for $1 \mathrm{~min}$ to separate the insoluble copper(I) oxide particles, and finally divided into aliquots of the final compound stock solution (Supplementary Scheme S2).

Alternatively, the click reaction could be performed in an Eppendorf tube and stirred with a suitable mixer.

We observed that the catalytic performance of the copper(I) oxide may vary significantly from batch to batch, therefore the actual reaction time should be adjusted accordingly in order to obtain a $\geq 95 \%$ conversion of the starting material and a $\left(\mathrm{TCP}_{\text {fast }}\right)$ :(hydrolyzed $\left.\mathrm{TCP}_{\text {fast }}\right)$ ratio greater than 3 (Supplementary Figure S9).
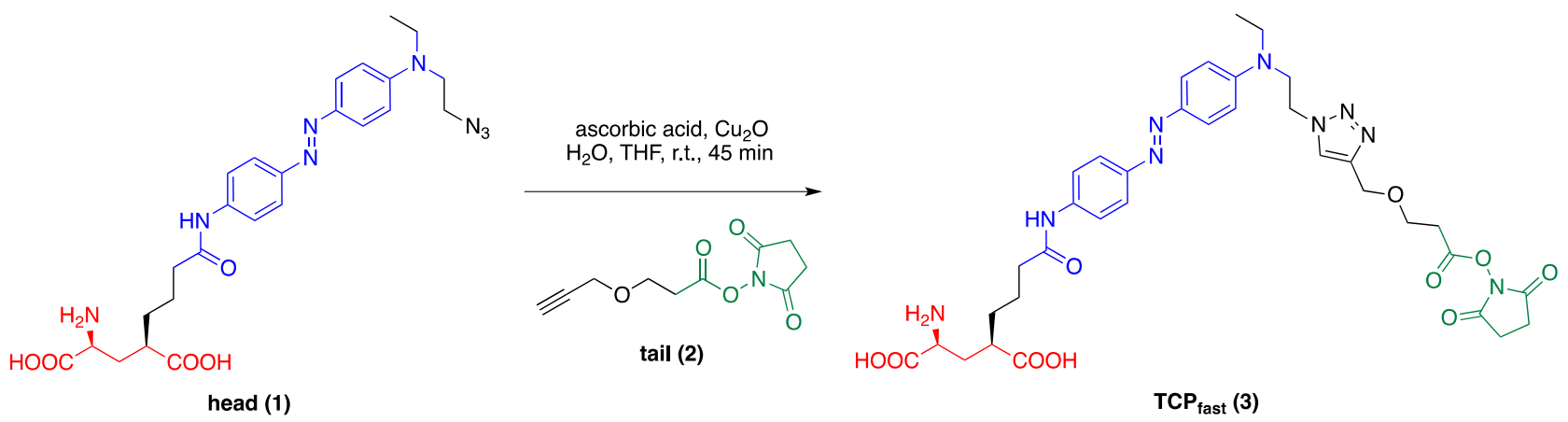

Supplementary Scheme S2. Preparation of TCP fast via Cu(I)-catalyzed azide-alkyne 1,3-dipolar cycloaddition ("click") reaction. 

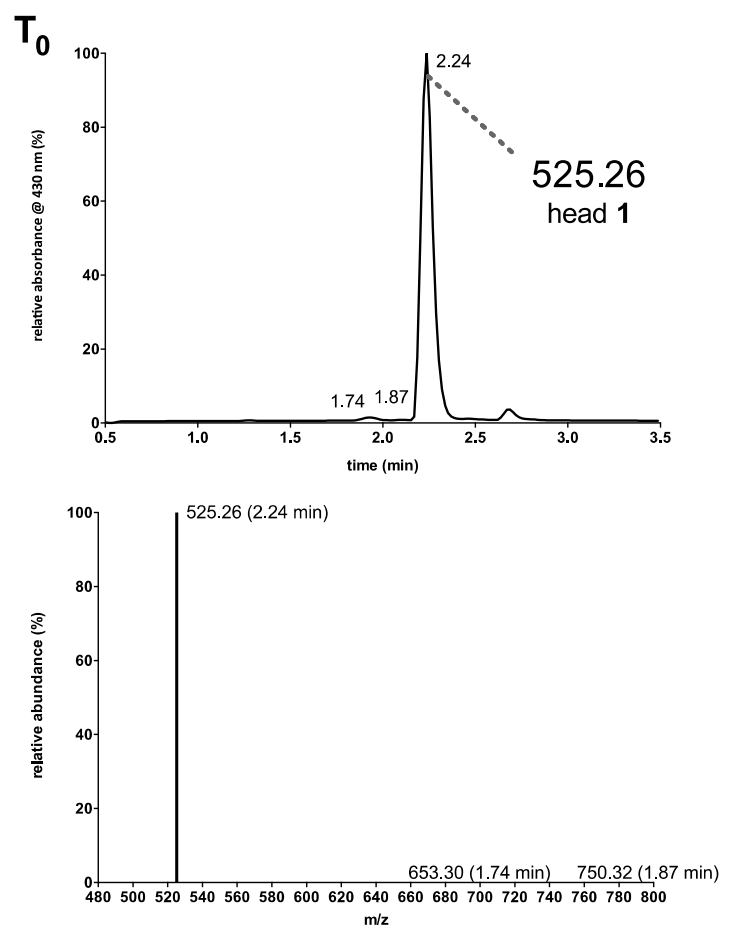
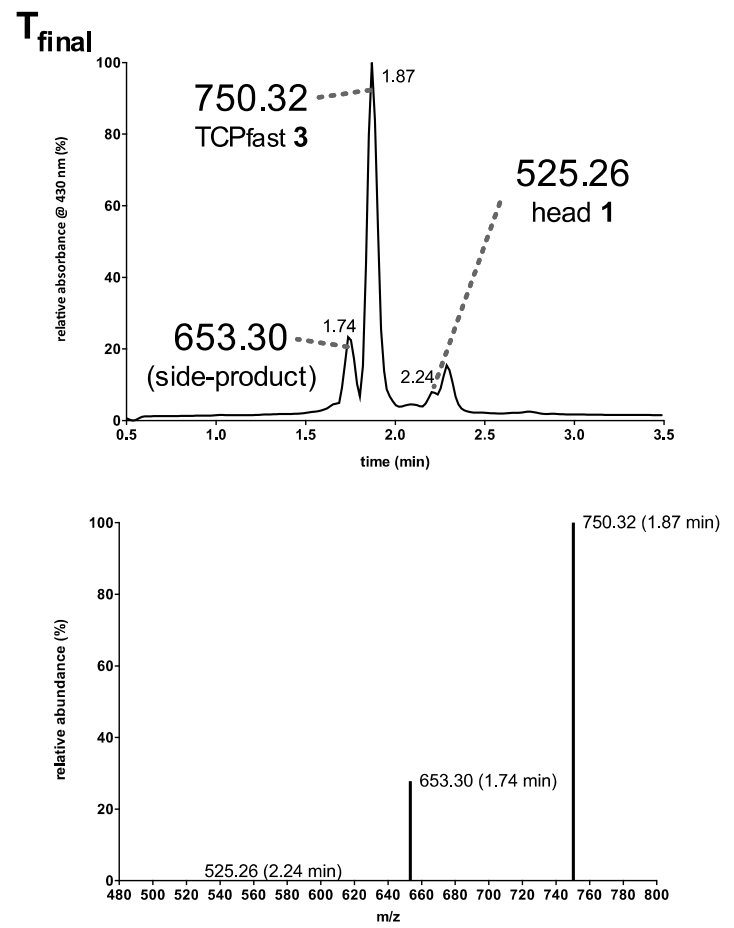

Supplementary Figure S9. Analysis of the initial and final mixture of a representative "click" reaction for the preparation of TCP fast (3), showing the conversion of the starting material to the final desired product and its side-product [top: HPLC chromatograms; $y$-axis shows relative absorbance (\%) at $430 \mathrm{~nm}$; bottom: selected ion recording (SIR) of the corresponding HPLC chromatograms for head (1), TCP fast $(\mathbf{3})$ and its major side-product; $y$-axis shows relative abundance (\%) of the ion species; see also Supplementary Scheme S3 for further details].

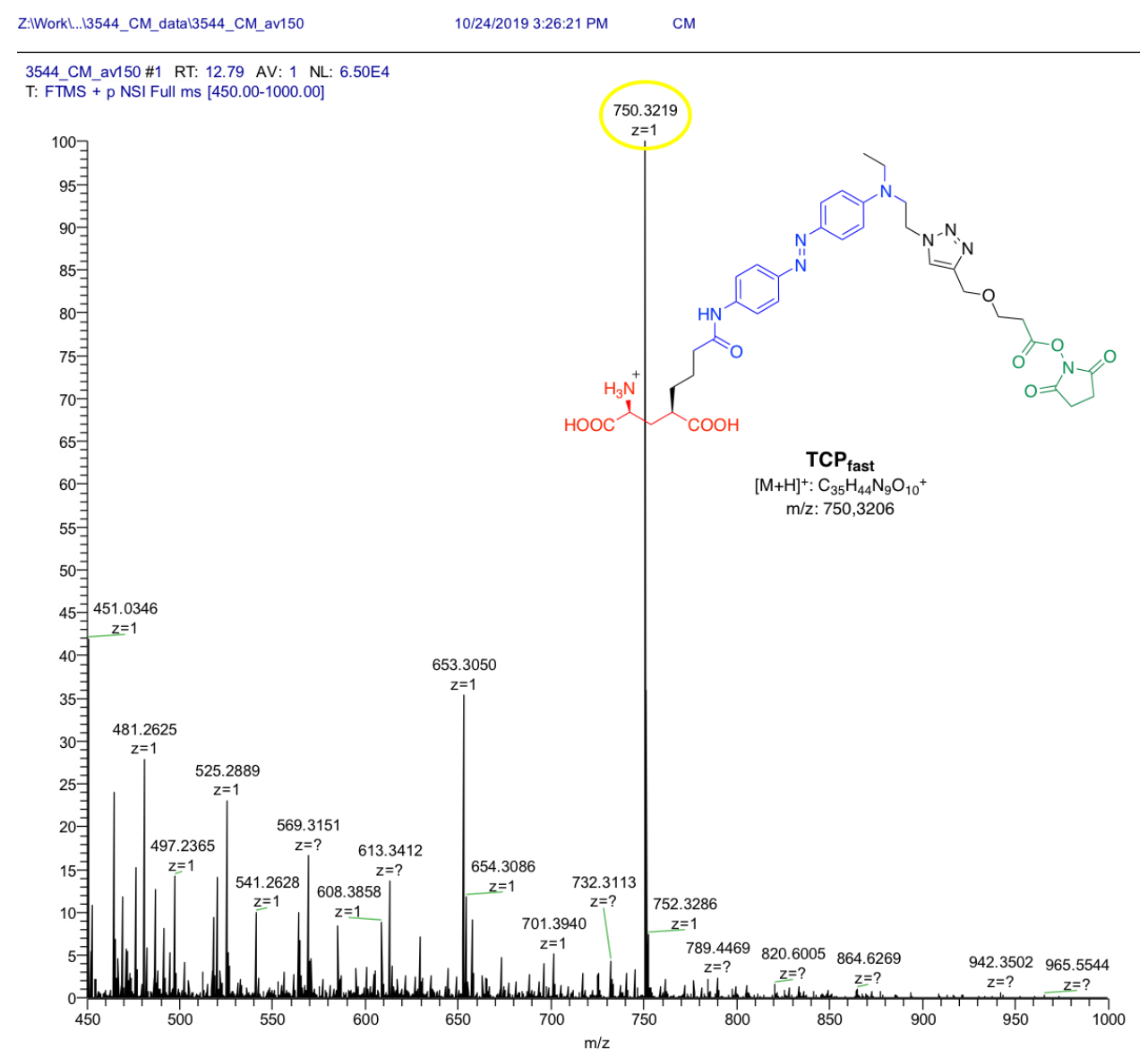

Supplementary Figure S10. High-resolution mass spectrum of TCP fast $(3)$. 


\section{Characterization of TCP fast, lysine-adduct, and side-product by LC-MS}
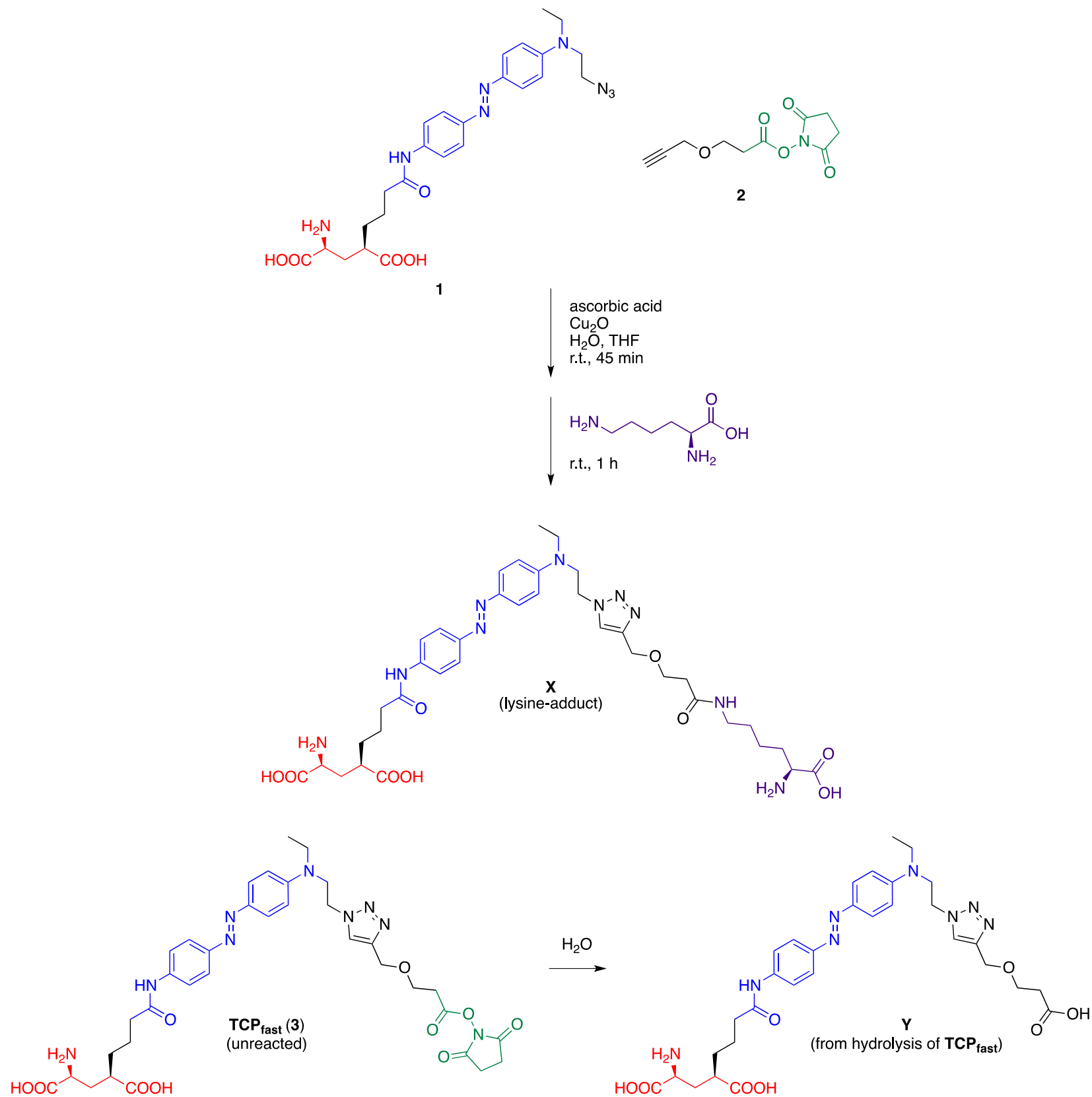

Supplementary Scheme S3. Generation and structure of the TCP fast-lysine adduct $(\mathbf{X})$ and detected main side-product

$(\mathbf{Y})$. 


\begin{tabular}{|c|c|c|}
\hline Compound & $\begin{array}{l}m / z \\
\text { calculated } \\
\text { for }[M+H]^{+}\end{array}$ & $\begin{array}{l}m / z \\
\text { calculated for } \\
{[\mathrm{M}+2 \mathrm{H}]^{2+}}\end{array}$ \\
\hline 1 & $\begin{array}{l}\mathrm{C}_{25} \mathrm{H}_{33} \mathrm{~N}_{8} \mathrm{O}_{5}{ }^{+}: \\
525.26\end{array}$ & $\begin{array}{l}\mathrm{C}_{25} \mathrm{H}_{34} \mathrm{~N}_{8} \mathrm{O}_{5}{ }^{2+}: \\
263.13\end{array}$ \\
\hline $\mathrm{TCP}_{\text {fast }}(3)$ & $\begin{array}{l}\mathrm{C}_{35} \mathrm{H}_{44} \mathrm{~N}_{9} \mathrm{O}_{10} 0^{+}: \\
750.32\end{array}$ & $\begin{array}{l}\mathrm{C}_{35} \mathrm{H}_{45} \mathrm{~N}_{9} \mathrm{O}_{10}{ }^{2+}: \\
375.66\end{array}$ \\
\hline$X$ & $\begin{array}{l}\mathrm{C}_{37} \mathrm{H}_{53} \mathrm{~N}_{10} \mathrm{O}_{9}^{+}: \\
781.40\end{array}$ & $\begin{array}{l}\mathrm{C}_{37} \mathrm{H}_{54} \mathrm{~N}_{10} \mathrm{O}_{9}{ }^{2+}: \\
391.20\end{array}$ \\
\hline $\mathbf{Y}$ & $\begin{array}{l}\mathrm{C}_{31} \mathrm{H}_{41} \mathrm{~N}_{8} \mathrm{O}_{8}{ }^{+}: \\
653.30\end{array}$ & $\begin{array}{l}\mathrm{C}_{31} \mathrm{H}_{42} \mathrm{~N}_{8} \mathrm{O}_{8}{ }^{2+}: \\
327.16\end{array}$ \\
\hline
\end{tabular}

Supplementary Table S1. Calculated mass-to-charge $(\mathrm{m} / \mathrm{z})$ ratio for compounds $\mathbf{1}, \mathrm{TCP}_{\text {fast }}(\mathbf{3}), \mathbf{X}, \mathbf{Y}$.

XSelect C18 4.6x50mm 3.5 $\mu \mathrm{m}$ IBEC_PG_BTCP_CLICK7A

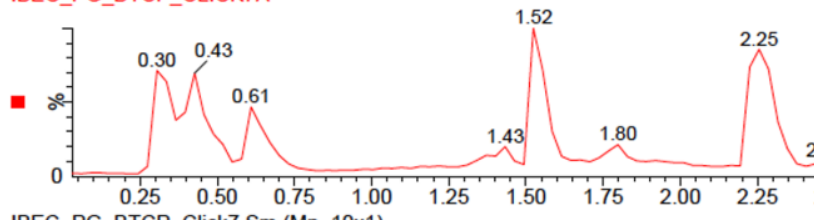

reaction profile

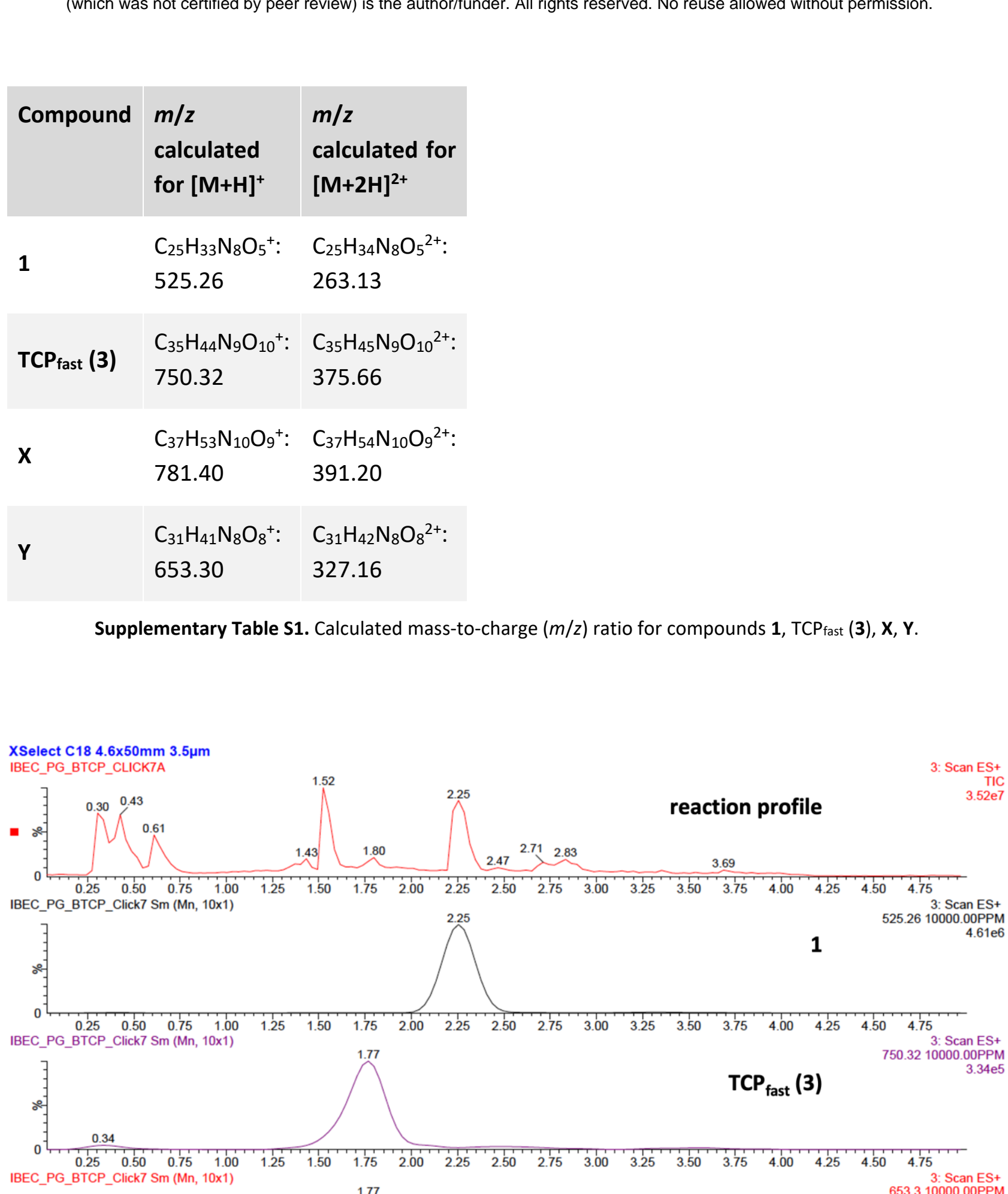
IBEC_PG_BTCP_Click7 Sm (Mn, 10x1)

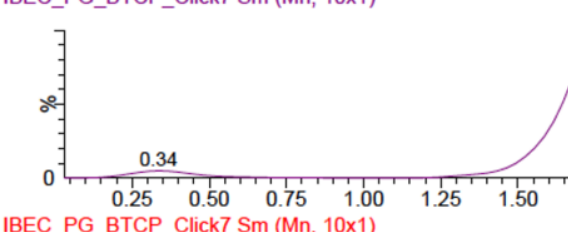

$\mathrm{TCP}_{\text {fast }}(\mathbf{3})$ IBEC_PG_BTCP_Click7 Sm (Mn, 10x1)

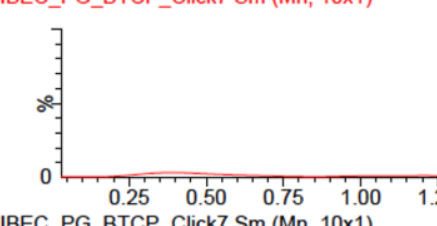

553.310000.00PPM

$\mathbf{Y}$ IBEC_PG_BTCP_Click7 Sm (Mn, 10x1)
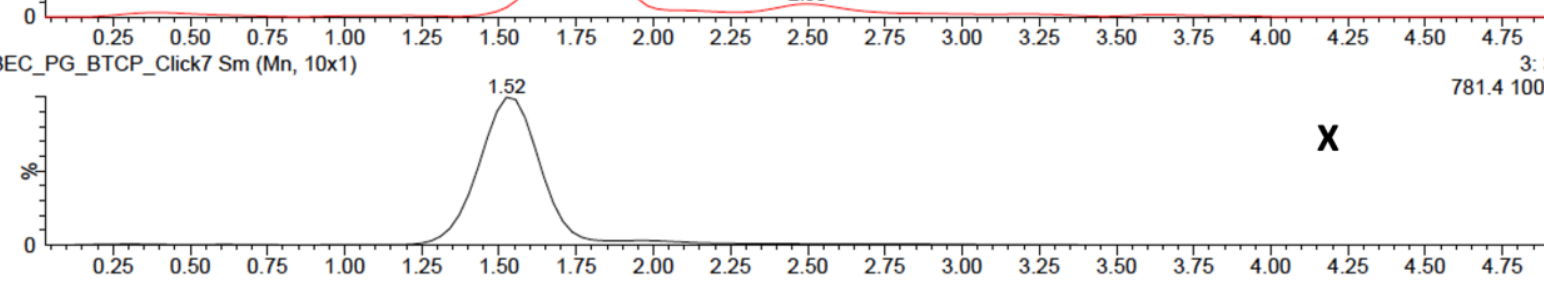

3: Scan ES+ 781.4 10000.00PPM

Supplementary Figure S11. LC-MS analysis of the final mixture for the reaction illustrated in Scheme S3 (arbitrary case). 
bioRxiv preprint doi: https://doi.org/10.1101/2021.05.25.445123; this version posted May 25, 2021. The copyright holder for this preprint

(which was not certified by peer review) is the author/funder. All rights reserved. No reuse allowed without permission.

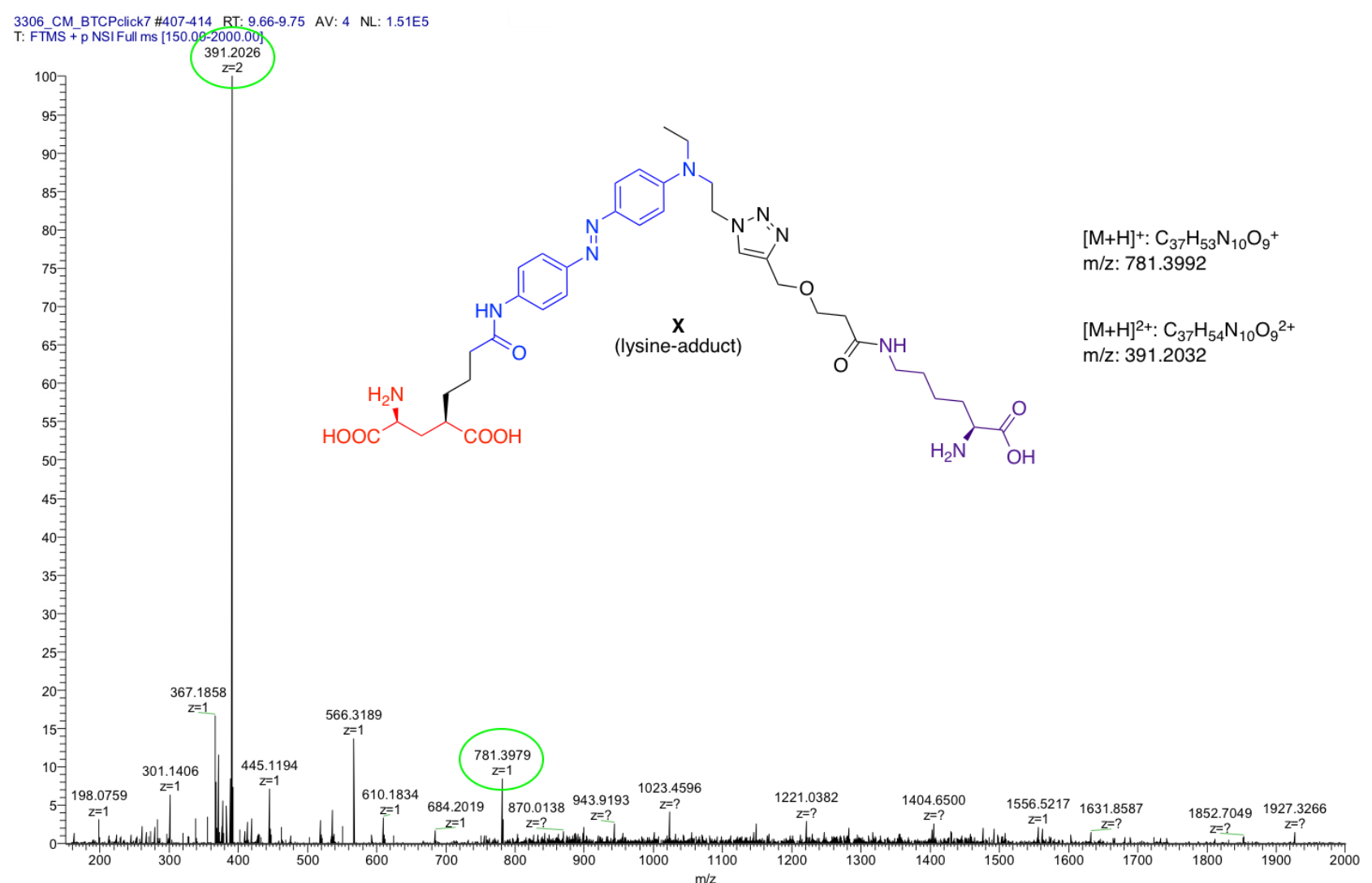

Supplementary Figure S12. High-resolution mass spectrum of the TCP fast-lysine adduct (X). 


\section{Characterization of $\mathrm{TCP}_{\text {fast }}$ in cultured neurons}

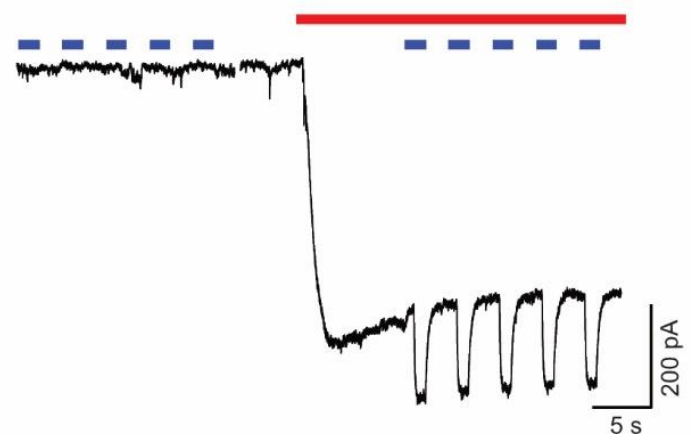

Supplementary Figure S13. TCP fast conjugation produces photocurrents in untransfected hippocampal neurons in the presence of glutamate. Current recording in whole cell voltage clamp mode in dissociated hippocampal neurons after incubation in $\mathrm{TCP}_{\text {fast }}(100 \mu \mathrm{M}$ for $2 \mathrm{~min}$ at $\mathrm{pH}$ ). Inward current induced by bath perfusion of $300 \mu \mathrm{M}$ glutamate (red bar) and $473 \mathrm{~nm}$ light (blue bars, $1 \mathrm{~s}$ ). Time gap between traces corresponds to immediate subsequent recordings (< 2s).

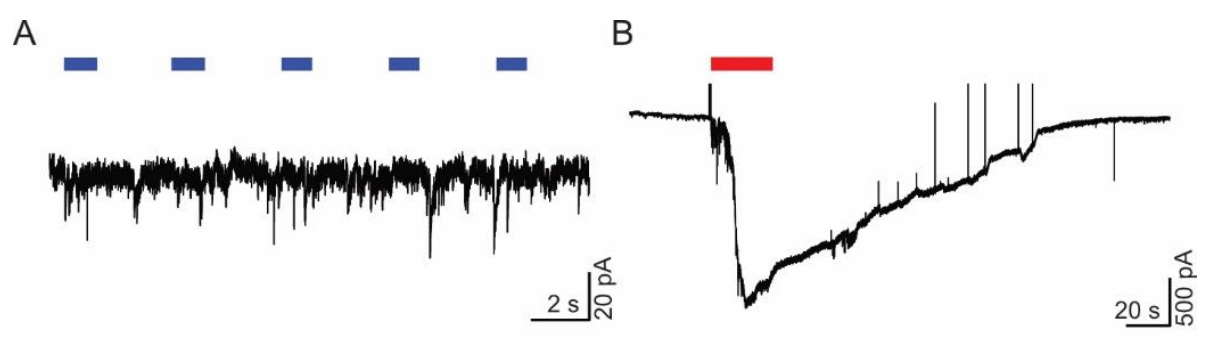

Supplementary Figure S14. Light stimulation does not affect neuronal responses prior to TCP fast incubation. A. Hippocampal neurons non-incubated with TCPfast do not respond to light (473 nm for $1 \mathrm{~s}$, blue bars). B. Physiological responses to glutamate perfusion ( $300 \mu \mathrm{M}$, red bar) indicate expression of glutamatergic receptors.

A

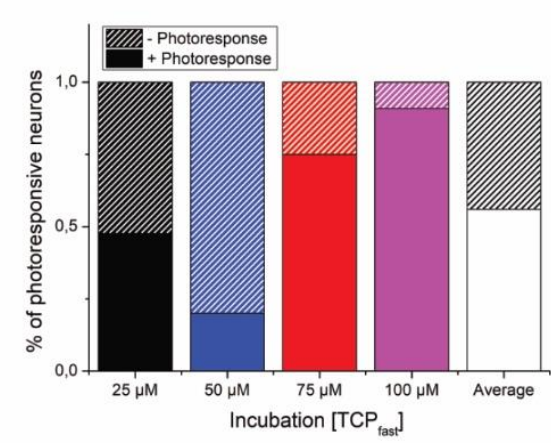

B

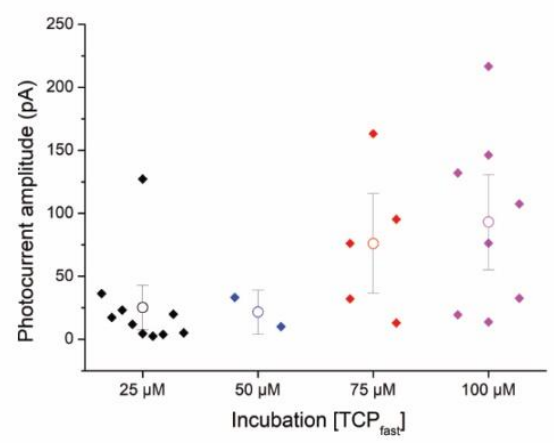

Supplementary Figure S15. Optimization of $\mathrm{TCP}_{\text {fast }}$ conjugation conditions to endogenous neural receptors in vitro. A. Increasing $\mathrm{TCP}_{\text {fast }}$ concentration during incubation ( $2 \mathrm{~min}, \mathrm{pH}$, 25-100 $\mu \mathrm{M}$ ) leads to a higher fraction of cells displaying photoresponses. Fresh $\mathrm{TCP}_{\text {fast }}$ was obtained after $45 \mathrm{~min}$ head-tail click coupling reaction. B. Photocurrent amplitude increases proportionally to concentration of $\mathrm{TCP}_{\text {fast }}$ incubated.

Note: From total num cells responding to perfusion of $300 \mu \mathrm{M}$ glutamate, $56 \%$ had light response. Per concentration, $47,62 \%$ of cells incubated at $25 \mu \mathrm{M}$ had light response $(n=21) ; 20 \%$ of cells incubated at $50 \mu \mathrm{M}$ had light response ( $n=10$ ); $75 \%$ of cells incubated at $75 \mu \mathrm{M}$ had light response $(n=8) ; 90 \%$ of cells incubated at $100 \mu \mathrm{M}$ had light response $(n=11)$. 
A

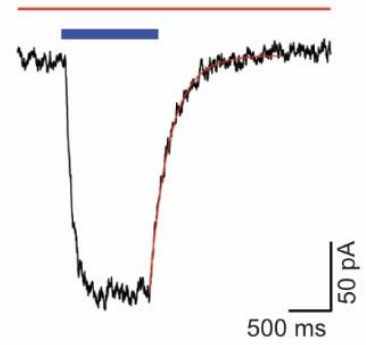

B

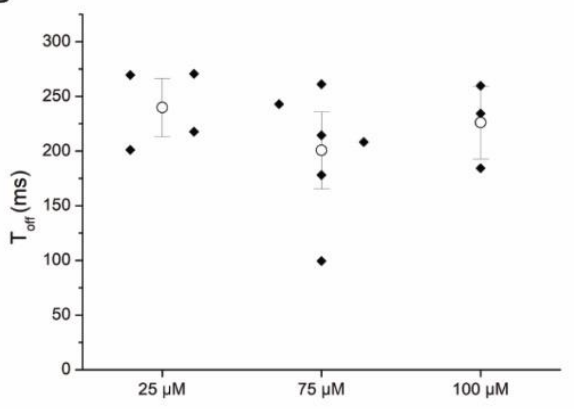

Supplementary Figure S16. Fast relaxation lifetime of TCP fast enables single wavelength control of photocurrents in hippocampal neurons. A. Representative current recording in response to $1 \mathrm{~s}$ blue light stimulation (blue bar) in presence of glutamate ( $300 \mu \mathrm{M}$, red bar) in bath solution. Whole cell voltage clamp mode recording in rat hippocampal neuron maintained 15 days in culture and incubated with TCP fast $(100 \mu \mathrm{M}$ for $2 \mathrm{~min}$ at pH9). Exponential fit of the photocurrent to obtain $\mathrm{T}_{\text {off }}$ is showed in red. B. Toff average values obtained in neurons incubated with TCP fast for $2 \mathrm{~min}$ at pH 9 at $25 \mu \mathrm{M}(n=4), 75 \mu \mathrm{M}(n=6)$ and $100 \mu \mathrm{M}(n=3)$. Each data point is the average of Toff values obtained from fitting 5 different light pulses in the same cell. White dot is mean \pm SE. The relaxation lifetime averaged for all concentrations is $220 \pm 48 \mathrm{~ms}$.

A

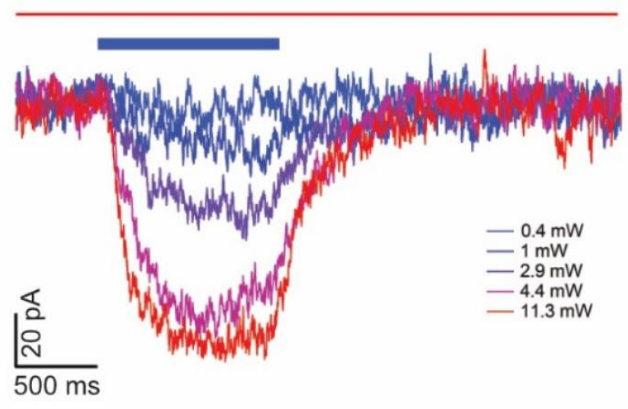

B

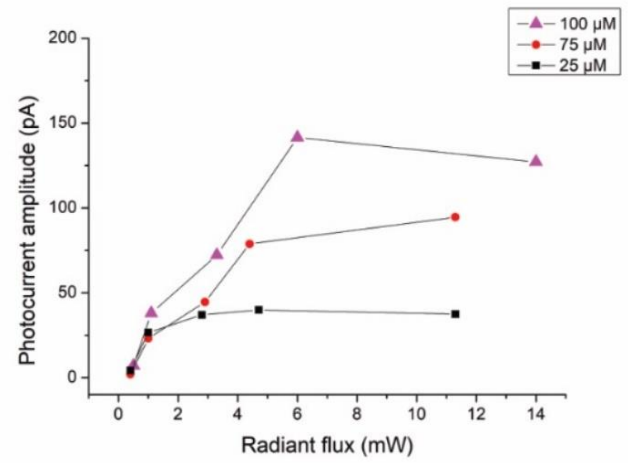

Supplementary Figure S17. Photocurrent amplitude depends on light intensity. A. Superimposed representative photocurrent responses to different light intensities $(473 \mathrm{~nm}, 1 \mathrm{~s})$ in the same neuron. Power values are indicated in the label. Whole cell voltage clamp mode recording in dissociated rat hippocampal neurons maintained 12 days in culture and incubated with TCP fast $(75 \mu \mathrm{M}$ for $2 \mathrm{~min}$ at $\mathrm{pH}$ ). B. Photocurrent amplitude as a function of radiant flux of different neurons incubated at different concentrations of TCP fast for 2 min at $\mathrm{pH} 9$. 
A

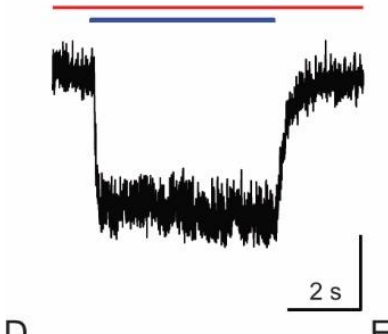

D

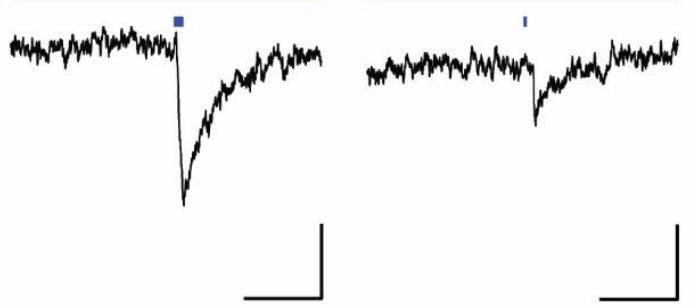

C

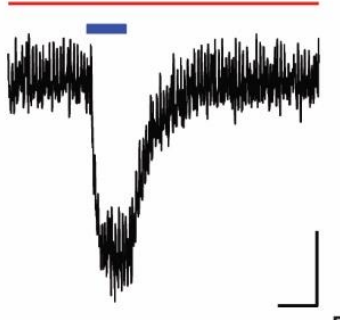

$\mathrm{F}$

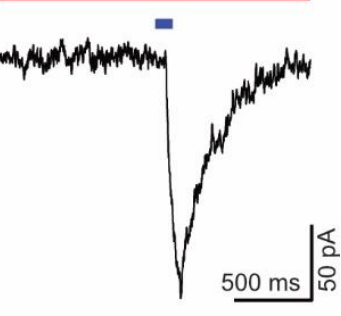

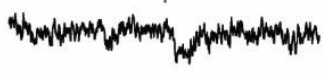

Supplementary Figure S18. Neurons incubated with $\mathrm{TCP}_{\text {fast }}$ display reversible cis-on photocurrents in response to blue light pulses as short as a few milliseconds. Current recording in whole cell voltage clamp mode of dissociated rat hippocampal neurons maintained 15 days in culture and incubated with TCP fast (100 $\mu \mathrm{M}$ for 2 min at pH9). Photocurrents elicited by illumination at $\lambda_{\mathrm{ex}}=473 \mathrm{~nm}$ and duration $5 \mathrm{~s}(\mathrm{~A}), 500 \mathrm{~ms}(\mathrm{~B}), 100 \mathrm{~ms}(\mathrm{C}), 50 \mathrm{~ms}(\mathrm{D}), 10 \mathrm{~ms}(\mathrm{E})$ and $3 \mathrm{~ms}(\mathrm{~F})$ in the presence of $300 \mu \mathrm{M}$ glutamate (red bar).

A Glu $300 \mu \mathrm{M}$

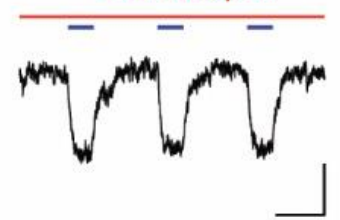

B
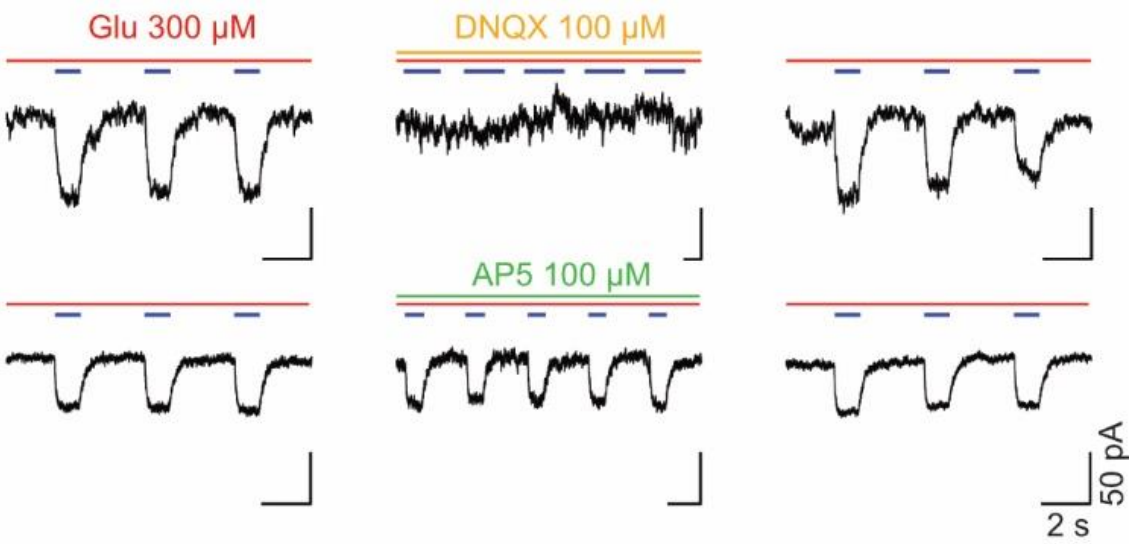

C
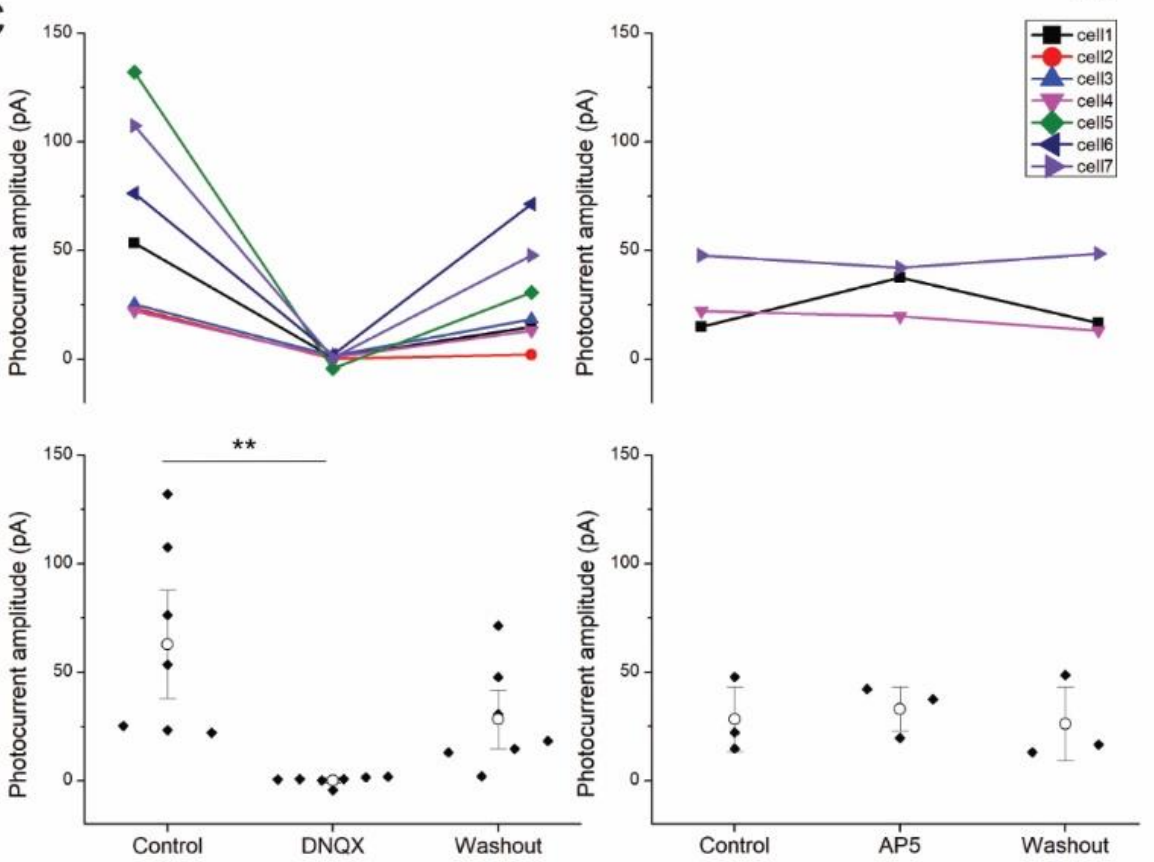
bioRxiv preprint doi: https://doi.org/10.1101/2021.05.25.445123; this version posted May 25, 2021. The copyright holder for this preprint (which was not certified by peer review) is the author/funder. All rights reserved. No reuse allowed without permission.

Supplementary Figure S19. TCP fast photocurrents in neurons are mediated by endogenous non-NMDA glutamate receptors.

A-B. Current recordings in whole cell voltage clamp mode in rat hippocampal neurons maintained 15 days in culture and incubated with $\mathrm{TCP}_{\text {fast }}(100 \mu \mathrm{M}$ for $2 \mathrm{~min}$ at $\mathrm{pH} 9)$. Example traces of photocurrents elicited by irradiation at $\lambda_{\mathrm{ex}}=$ $473 \mathrm{~nm}(1 \mathrm{~s}$, blue bars) in the presence of $300 \mu \mathrm{M}$ glutamate (red bar). Photocurrents are reversibly blocked by perfusion of $100 \mu \mathrm{M}$ DNQX (A, orange bar) and not affected by $100 \mu \mathrm{M}$ AP5 (B, green bar). After washout and reperfusion of 300 $\mu \mathrm{M}$ glutamate photocurrents are recovered.

C. Quantification of the effect of DNQX $(100 \mu \mathrm{M}, \mathrm{n}=7, \mathrm{p}$-value $=0.008)$ and AP5 $(100 \mu \mathrm{M}, \mathrm{n}=3, \mathrm{p}$-value $=0.56)$ on the photocurrent amplitude obtained from hippocampal neurons incubated with TCP fast (25-75-100 $\mu \mathrm{M} \mathrm{for} 2 \mathrm{~min}$ at pH9). Control and wash-out measurements were obtained after bath solution and glutamate perfusion. White dots indicate mean \pm SE.

Note: p-values obtained after performing Friedman test: nonparametric, data from any distribution; small samples; related samples. 


\section{In vivo photocontrol of neural activity in gerbil's cochlea}
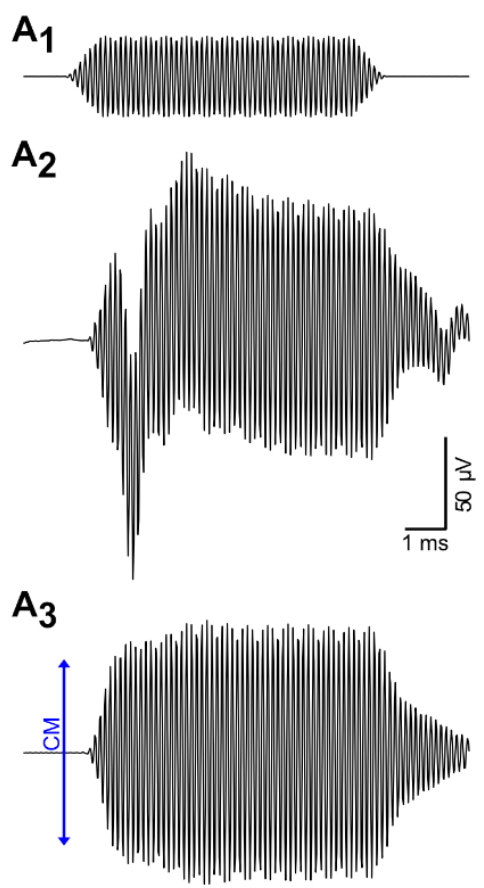

$\mathrm{A}_{4}$

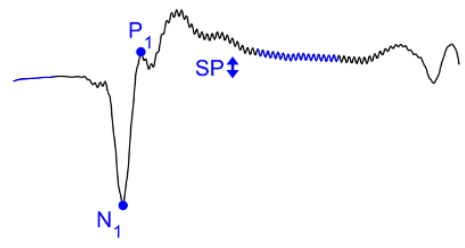

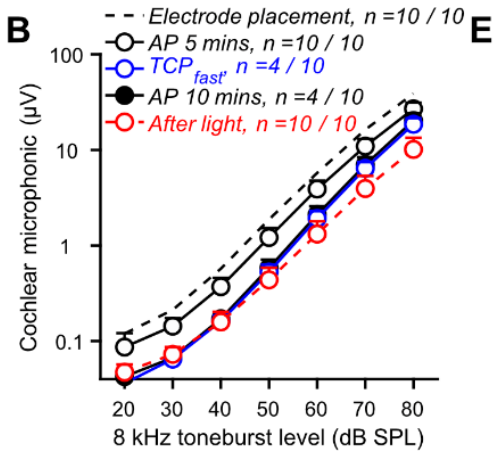
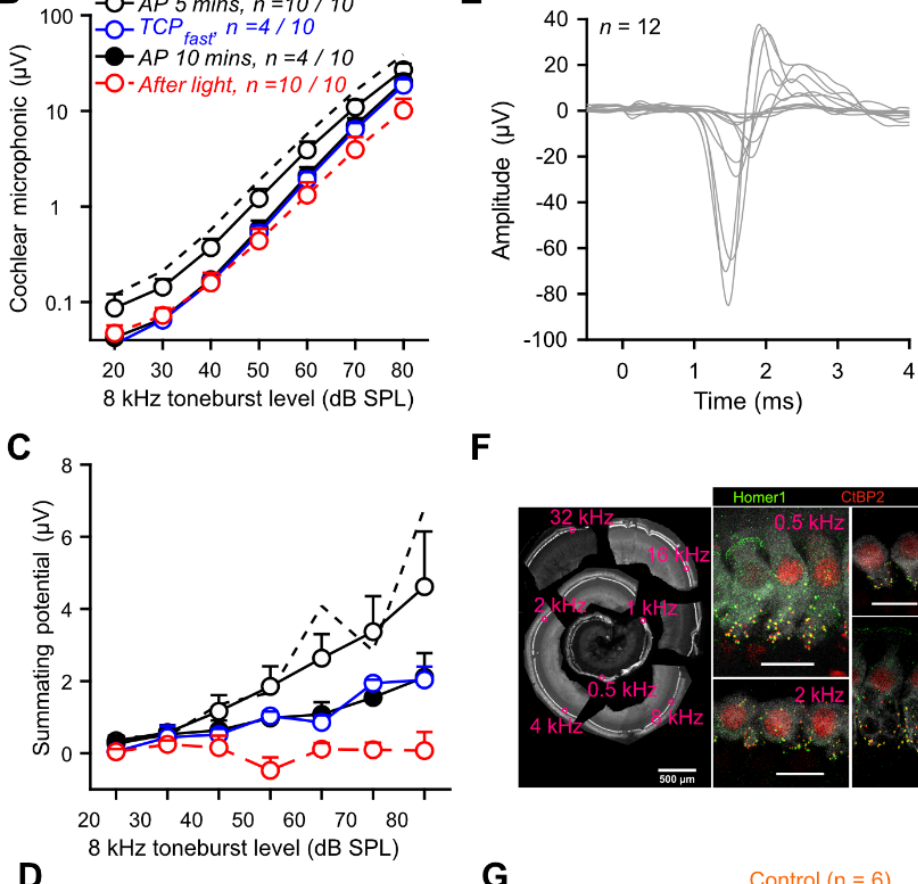

$\mathbf{F}$

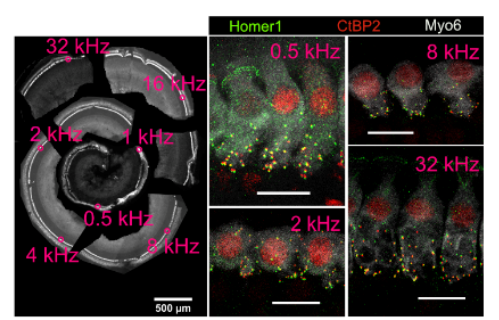

G

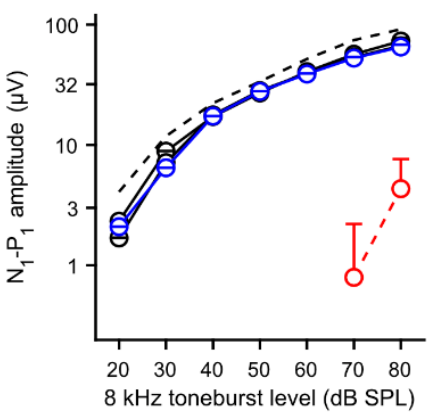

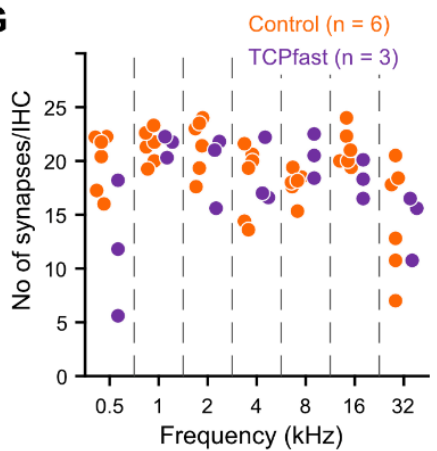

Supplementary Figure S20. $12.5 \mu \mathrm{M}$ TCP fast administration into the cochlea enables a transient optically evoked response of the SGNs followed by a loss of function of the inner hair cells and spiral ganglion neurons. A. Cochlear mass potentials $\left(A_{2}\right)$, recorded by a silver ball electrode implanted into the cochlear round window niche, in response to acoustic toneburst of $8 \mathrm{kHz}\left(A_{1}\right)$. The cochlear microphonic $\left(C M, A_{3}\right)$, reflecting outer hair cells activity, is extracted from the mass potential by a band passed filter centered on the stimulation frequency. The summating potential (SP, $\left.A_{4}\right)$, reflecting inner hair cell activity, is measured as the difference between the base line and the plateau potential of the low-passed $\left(<3.5 \mathrm{kHz}\right.$ ) filtered mass potential. The compound action potential ( $\left.C A P, A_{4}\right)$, reflecting the synchronous SGN first spike evoked by the sound stimulation, is measured as the difference between the negative peak $\mathrm{N}_{1}$ and the positive peak $P_{1}$. B-D. Quantification (mean \pm SEM) of the cochlear microphonic (B), summating potential (C) and CAP (D) as a function of the stimulation level after electrode placement (dashed line, $n=10$ ), 5 min after artificial perilymph (AP) application defining the base line (open black circle, $n=10$ ), following $12.5 \mu \mathrm{M} \mathrm{TCP}$ fast application (open blue circle, $n=4), 10$ min rinsing with AP (close dark circle, $n=4$ ) and following light stimulation (red open circle, $n=10)$. E. Transient optically evoked CAPs (oCAP) recorded from 12 treated cochleae with $12.5 \mu \mathrm{M}$ TCP fast. F. Right: Maximum projections of confocal stacks of immunolabelled gerbil IHC afferent synapses (IHC, anti-Myo6, gray; pre-synapse, antiCtBP2/RIBEYE, red; post-synapse, anti-Homer1, green) at different tonotopic location (scale bar = $10 \mu \mathrm{m}$ ). Left: Montage of the low-magnification view of fragments of the full gerbil organ of Corti (scale bar $=500 \mu \mathrm{m}$ ). G. Quantification of the number of synapses per IHC between non-treated $(n=6)$ and $12.5 \mu \mathrm{M} \mathrm{TCP}$ fast treated $(n=3)$ cochleae at different tonotopic regions $(0.5,1,2,4,8,16$ and $32 \mathrm{kHz})$. 
A

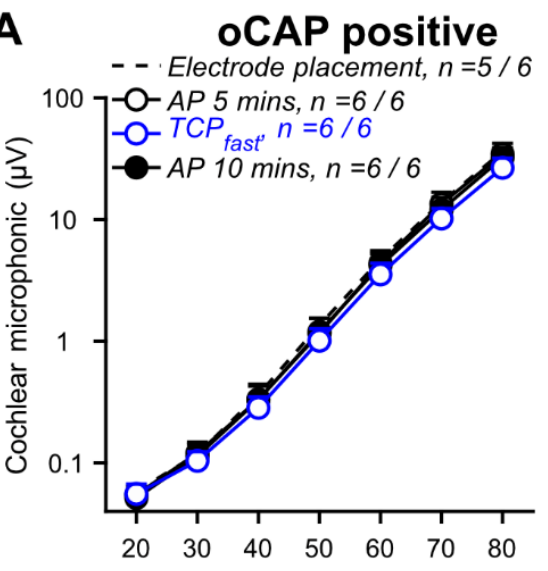

B

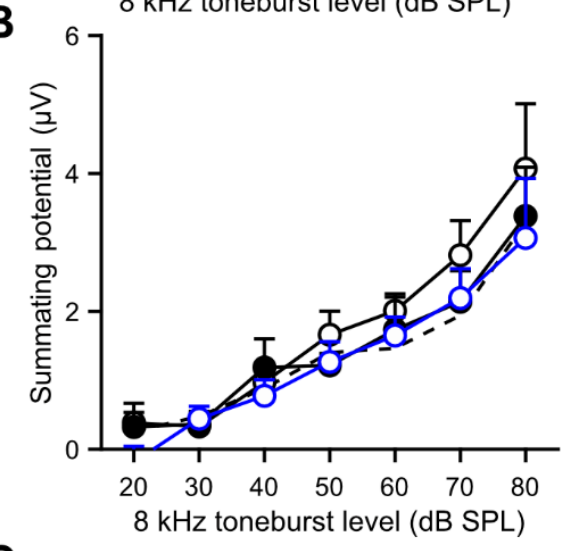

C

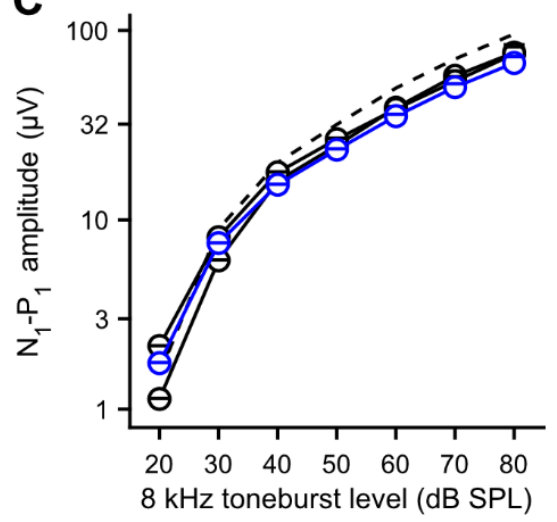

D OCAP negative

- - Electrode placement, $n=4 / 4$

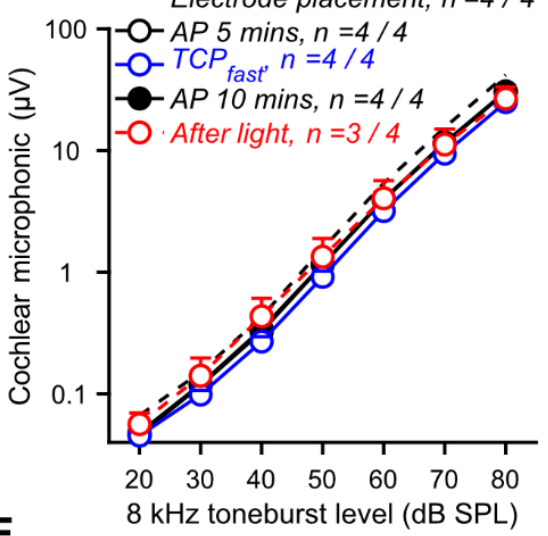

E

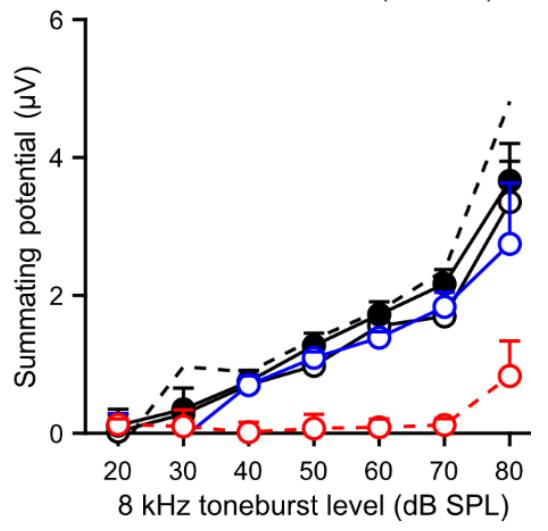

$\mathbf{F}$

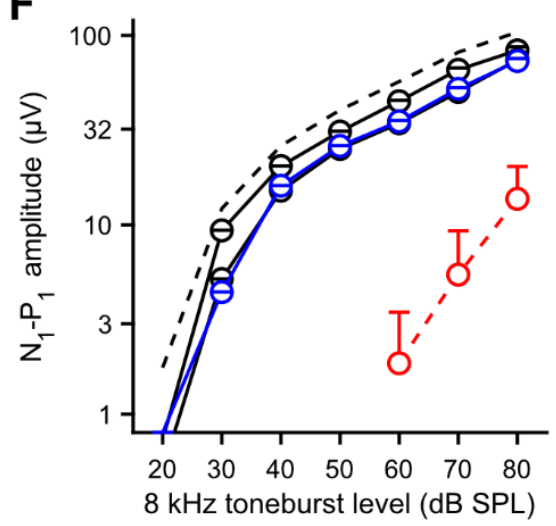

Supplementary Figure $\mathbf{S 2 1}$. In $60 \%$ of the cases $2.5 \mu \mathrm{M}$ TCP fast application into the cochlea allows stable photoresponse in absence of toxicity for the organ of Corti. A-F. Quantification (mean \pm SEM) of the cochlear microphonic $(A, D)$, summating potential $(B, E)$ and $C A P(C, F)$ as a function of the stimulation level after electrode placement (dashed line), 5 min after artificial perilymph (AP) application defining the base line (open black circle), following $12.5 \mu \mathrm{M}$ TCPfast application (open blue circle), 10 min rinsing with AP (close dark circle) and following light stimulation (red open circle) for the cochleae from which stable optically evoked CAPs were recorded (oCAP positive) or not (oCAP negative). 

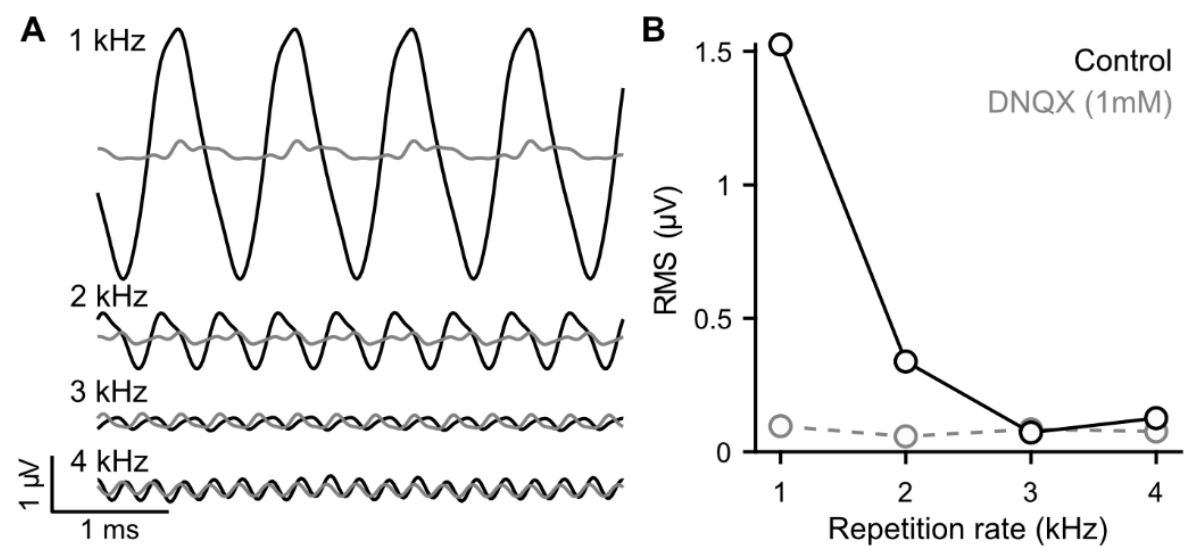

Supplementary Figure S22. TCP fast enables AMPA-mediated oCAPs up to stimulation rate of $\mathbf{2}$ kHz. A. oCAPs recorded from one cochlea in response to 1, 2, 3 and $4 \mathrm{kHz}$ repetition rate before (black) and after DNQX (1 mM, gray). B. Measure of the oCAP amplitude (illustrated in A) as a function of the repetition rate before (black) and after DNQX application (gray). 
bioRxiv preprint doi: https://doi.org/10.1101/2021.05.25.445123; this version posted May 25, 2021. The copyright holder for this preprint (which was not certified by peer review) is the author/funder. All rights reserved. No reuse allowed without permission.

\section{Supplementary references}

Himo F, Lovell T, Hilgraf R, Rostovtsev VV, Noodleman L, Sharpless KB \& Fokin VV (2005) Copper(I)Catalyzed Synthesis of Azoles. DFT Study Predicts Unprecedented Reactivity and Intermediates. J Am Chem Soc 127: 210-216

Volgraf M, Gorostiza P, Numano R, Kramer RH, Isacoff EY \& Trauner D (2006) Allosteric control of an ionotropic glutamate receptor with an optical switch. Nat Chem Biol 2: 47-52 